\title{
1 Targeting acute myeloid leukemia by drug-induced c-MYB degradation
}

2

3 Vanessa Walf-Vorderwülbecke ${ }^{1}$, Kerra Pearce ${ }^{2}$, Tony Brooks ${ }^{2}$, Mike Hubank ${ }^{2}$, Marry M van 4 den Heuvel-Eibrink ${ }^{3,4}$, C Michel Zwaan ${ }^{3}$, Stuart Adams ${ }^{5}$, Darren Edwards ${ }^{6}$, Jack Bartram ${ }^{6}$, 5 Sujith Samarasinghe ${ }^{6}$, Philip Ancliff ${ }^{6}$, Asim Khwaja $^{7}$, Nicholas Goulden ${ }^{6}$, Gareth Williams ${ }^{8, *}$, 6 Jasper de Boer ${ }^{1, *}$ and Owen Williams ${ }^{1, *}$

$7 \quad{ }^{1}$ Cancer Section, Developmental Biology and Cancer Programme, UCL Great Ormond Street 8 Institute of Child Health, London, United Kingdom; ${ }^{2}$ UCL Genomics, UCL Great Ormond 9 Street Institute of Child Health, London, United Kingdom; ${ }^{3}$ Department of Pediatric Oncology/Hematology, Erasmus-MC Sophia Children's Hospital, Rotterdam, Netherlands; ${ }^{4}$ Princess Maxima Center for Pediatric Oncology, Utrecht, Netherlands; ${ }^{5}$ SIHMDSHaematology, Great Ormond Street Hospital for Children, London, United Kingdom; ${ }^{6}$ Department of Paediatric Haematology, Great Ormond Street Hospital for Children, London, United Kingdom; ${ }^{7}$ Department of Haematology, UCL Cancer Institute, London, UK; ${ }^{8}$ Wolfson Centre for Age-Related Diseases, King's College London, London, UK.

Correspondence: Owen Williams or Jasper de Boer, Cancer Section, Developmental Biology and Cancer Programme, UCL GOSICH, 30 Guilford Street, London WC1N 1EH, UK. Phone: +44-207-9052180; E-mail: owen.williams@ucl.ac.uk or j.boer@ucl.ac.uk; Fax: +44207-9052339.

*These authors contributed equally to this work.

Conflict of Interest statement: the authors have no conflict of interest to declare.

Running title: Mebendazole induced c-MYB degradation in AML 


\section{ABSTRACT}

24 Despite advances in our understanding of the molecular basis for particular subtypes of acute 25 myeloid leukemia (AML), effective therapy remains a challenge for many individuals 26 suffering from this disease. A significant proportion of both pediatric and adult AML patients

27 cannot be cured and since the upper limits of chemotherapy intensification have been reached, there is an urgent need for novel therapeutic approaches. The transcription factor cMYB has been shown to play a central role in the development and progression of AML driven by several different oncogenes, including mixed lineage leukemia $(M L L)$-fusion genes. Here, we have used a $c-M Y B$ gene expression signature from $M L L$-rearranged AML to probe the Connectivity Map database and identified mebendazole as a c-MYB targeting drug. Mebendazole induces c-MYB degradation via the proteasome by interfering with the heat shock protein 70 (HSP70) chaperone system. Transient exposure to mebendazole is sufficient to inhibit colony formation by AML cells, but not normal cord blood-derived cells.

36 Furthermore, mebendazole is effective at impairing AML progression in vivo in mouse

37 xenotransplantation experiments. In context of the widespread human use of mebendazole, our data indicate that mebendazole induced c-MYB degradation represents a safe and novel therapeutic approach for AML. 
41 Rational combination of intensive chemotherapy with risk stratification has revolutionized

42 the treatment of acute leukemia in children. However, progress has not been uniform across 43 all subtypes of disease and many pediatric ${ }^{1}$ and adult ${ }^{2}$ Acute Myeloid Leukemia (AML) patients cannot be cured by current therapies. It is widely accepted that further intensification of chemotherapy is unlikely to improve outcomes, ${ }^{3,4}$ but that this may be achieved by developing novel therapeutics targeting specific leukemia drug-susceptibilities.

Rearrangements of the $M L L$ gene are often associated with AML in children, and less frequently in adults. ${ }^{5}$ These abnormalities result in generation of MLL fusion proteins, which are responsible for driving development of the disease. These proteins hijack the normal epigenetic machinery in developing hematopoietic cells, enforcing transcriptional dysregulation of target genes. ${ }^{6-9}$ Identification of components of the MLL fusion-associated complexes led to a number of drug discovery initiatives. ${ }^{10,11}$ Recent studies indicate that one transcriptional target in particular, encoding the transcription factor c-MYB, is responsible for maintaining aberrant hematopoietic self-renewal programs necessary for initiation and progression of $M L L$-rearranged AML. ${ }^{12-15}$

c-MYB is highly expressed in immature hematopoietic progenitor cells and is required for definitive hematopoiesis, ${ }^{16}$ normal myelopoiesis ${ }^{17}$ and maintenance of adult hematopoietic stem cell (HSC) self-renewal. ${ }^{18} c-M Y B$ is rarely mutated in human leukemia, but has long been associated with hematopoietic malignancies. ${ }^{19,20}$ Some leukemia cells have been shown to be more sensitive to c-MYB inhibition than normal hematopoietic cells. ${ }^{21,22}$ This led to the hypothesis that although it may not be an oncogenic driver itself, certain cancers are nevertheless 'addicted' transcriptional dysregulation by c-MYB. ${ }^{23}$ In contrast to absolute cMYB deficiency, low levels of c-MYB expression are compatible with limited 
64 hematopoiesis, especially myelopoiesis, ${ }^{15,} 24$ suggesting that a window may exist for 65 therapeutic targeting of c-MYB in AML. However, difficulties associated with developing 66 small molecule inhibitors of transcription factor activity suggest that alternative approaches 67 may be required to target c-MYB. ${ }^{19}$ For example, the interaction between c-MYB and the 68 transcriptional co-activator p300 was recently shown to be essential for AML induction ${ }^{25}$ and 69 to have promising potential as a target for pharmacological inhibition. ${ }^{26}$

70 In order to identify bioactive compounds capable of inhibiting c-MYB transcriptional 71 activity in AML, we screened the Connectivity Map (CMAP) database with a c-MYB gene 72 expression signature derived from integrating MLL-fusion protein specific gene expression 73 changes with a list of previously published direct c-MYB target genes. ${ }^{27,}{ }^{28}$ This analysis 74 identified the anti-helminth drug mebendazole as the top hit. We demonstrate that 75 mebendazole induces proteasomal degradation of c-MYB, inhibits AML cell self-renewal 76 and impairs AML progression in vivo. This work demonstrates that mebendazole has 77 excellent potential for repurposing in novel AML therapies. 


\section{MATERIALS AND METHODS}

Mice

Mice were maintained in the UCL GOSICH animal facilities and experiments were performed according to and approved by the United Kingdom Home Office regulations and followed UCL GOSICH institutional guidelines.

\section{Human samples}

For human AML samples (Supplementary Table 1), approval by the Institutional Review Board of the Erasmus MC for use of excess diagnostic material was obtained according to laws and regulations of the Netherlands, DB AML 01 (MEC-2010-370), AML NOPHO DBH 2012 (MEC-2014-024).

Global gene expression, SPIEDw and Gene set enrichment (GSEA) analyses Analysis of MLL-ENL/MLL-AF9 gene expression changes (Geo repository: GSE59236) was performed using Affymetrix arrays (Affymetrix UK, High Wycombe, UK) and conditionally immortalized MLL-ENL and MLL-AF9 mouse myeloid cells. ${ }^{29-32}$ Gene expression changes resulting from 6 hours exposure of THP1 cells to $10 \mu \mathrm{M}$ mebendazole or DMSO were analysed by RNA-sequencing (Geo repository: GSE96544). A list (Supplementary Table 2) of human orthologs of MLL-ENL/MLL-AF9 gene expression changes, for genes also contained in the list of 1063 genes bound by c-MYB in mouse myeloid ERMYB cells ${ }^{27}$ and deregulated in THP1 cells following siRNA-mediated c-MYB silencing, ${ }^{28}$ were used to interrogate the CMAP database (https://portals.broadinstitute.org/cmap/) ${ }^{33}$ using the SPIEDw web tool ${ }^{34}$ (http://www.spied.org.uk/). For GSEA, c-MYB signatures were derived from Zhao et al. ${ }^{27}$ and LSC signatures from Somervaille et al. ${ }^{13}$ 
105 Cell culture and reagents

106 Human AML cell lines were purchased from the ATCC (THP1) and DSMZ (OCI-AML3, 107 NOMO-1, KCL22, U937, MV4;11, KASUMI-1 and SHI-1), authenticated by short tandem 108 repeat profiling using the PowerPlex 16 system (Promega, Southampton, UK) and mycoplasma negative status confirmed using the MycoAlert Mycoplasma Detection Kit (Lonza, Verviers, Belgium). 293FT cells were from ThermoFisher Scientific (ThermoFisher Scientific, Hemel Hempstead, UK) and immortalized mouse myeloid cells were cultured as 112 previously described. ${ }^{29-32}$

114 Colony formation assays

115 AML cell lines were plated in HSC002 (Bio Techne, Abingdon, UK), normal CD34 ${ }^{+}$cord blood-derived cells (ZenBio, NC, USA) in HSC005 (Bio Techne) and primary AML cells in HSC005 methylcellulose medium supplemented with $50 \mathrm{ng} / \mathrm{ml}$ TPO and FLT3L.

Nematic protein organisation technique (NPOT) analysis

NPOT analysis was performed by INOVIEM Scientific (INOVIEM Scientific, Strasbourg, France).

In vivo transplantation

124 Luciferase expressing THP1 cells were transplanted into non-irradiated NOD-SCID- $\gamma^{-/-}$ (NSG; The Jackson Laboratory, Bar Harbor, ME, USA) mice. Recipient mice were imaged using the IVIS® Lumina Series III (PerkinElmer, Beaconsfield, UK) and randomly allocated 127 to control or mebendazole-treated groups. Mebendazole (200 $\mathrm{mg} / \mathrm{kg}$ of diet) was administered ad libitum in regular powdered diet, changed daily. 
Lentivirus vector cloning

131 The $\triangle \mathrm{MYB} \mathrm{cDNA}^{35}$ was cloned into the pCSGW-PIG vector, made by replacing the GFP 132 cDNA from pCSGW $^{36}$ with a puro-IRES-GFP cassette. Lentiviral MISSION shRNA constructs targeting c-MYB (Clone ID:NM_005375.2-927s21c1), HSPA1A (sh1:Clone ID:NM_005345.4-1539s1c1; sh2:Clone ID:NM_005345.4-566s1c1) and the scramble (SCR) non-silencing control (SHC002) were purchased from Sigma-Aldrich (Gillingham, UK).

Western blot analysis

Antibodies against c-MYB (H-141, catalogue number sc-7874, Santa Cruz Biotechnology,

Dallas, TX, USA; clone 1-1, catalogue number 05-175, Merck Millipore, Watford, UK; EPR718(2), catalogue number ab109127 , Abcam, Cambridge, UK), HSP70 (clone 242707, catalogue number MAB1663, Bio Techne), HSP70/HSC70 (and H-300, catalogue number sc33575, and W27, catalogue number sc-24, Santa Cruz Biotechnology), Actin (I-19, catalogue number sc-1616, Santa Cruz Biotechnology), $\beta$-Actin (C4, catalogue number sc-47778, Santa

Cruz Biotechnology), $\alpha$ Tubulin (YL1/2, catalogue number sc-53029, Santa Cruz

Biotechnology), SP1 (PEP 2, catalogue number sc-59, Santa Cruz Biotechnology) .

Microtubule depolymerization assay

Microtubule depolymerization was analysed as published previously. ${ }^{37}$

Quantitative RT-PCR analysis

Quantitative RT-PCR (qPCR) was performed on isolated mRNA using TaqMan probe based chemistry and an ABI Prism 7900HT fast Sequence Detection System (Life Technologies, Paisley, UK). All primer/probe sets were from Applied Biosystems, Life Technologies. 
155 Statistics

156 Statistical significance was determined using Prism (GraphPad) software. Statistical analysis

157 of survival curves was performed using the Mantel-Haenszel log-rank test. Statistical analysis

158 of means was performed using the one sample $t$ test or unpaired Student's $t$ test, two-tailed $P$

159 values $<0.05$ being considered statistically significant. Variance was similar between groups.

160

161 Further details are provided in Supplementary Materials and Methods.

162 


\section{RESULTS}

164 To identify candidate anti-leukemia drugs, we generated a therapeutic signature

165 (Supplementary Table 2) by integrating gene expression changes due to MLL fusion silencing ${ }^{29-32}$ with transcriptional regulation by c-MYB in acute myeloid leukemia. ${ }^{27,}{ }^{28}$ This signature was then used to interrogate drug-induced gene expression profiles in the CMAP database $^{33}$ using the SPIEDw web tool ${ }^{34}$ (Figure 1a). The top hit resulting from this analysis was the anti-helminth agent mebendazole (Figure 1b).

In order to determine whether mebendazole was able to interfere with c-MYB regulated transcriptional pathways in human AML cells, RNASeq was performed on the MLL-AF9 expressing cell line THP1, following short-term exposure to the drug. GSEA of mebendazole induced gene expression changes confirmed that this drug was able to reverse both activation and repression by c-MYB of its target genes (Figure 1c and Supplementary Figure 1). Mebendazole exhibited anti-leukemia activity against $M L L$ rearranged and non-rearranged human AML cell lines (Figure 2a and Supplementary Figure 2) and was effective at blocking their colony forming activity (Figure $2 \mathrm{~b}$ and Supplementary Figure 3). This is not surprising, since c-MYB has also been shown to play a critical function in non-rearranged subtypes of

AML. ${ }^{25,}$ 26, 38-41 Indeed, shRNA mediated silencing of c-MYB expression had a severe impact on colony formation (Supplementary Figure 4).

We then examined whether mebendazole interfered with c-MYB regulated gene expression by targeting the transcription factor directly, by examining RNA and protein expression 6 hours after exposure of AML cells to the drug. Interestingly, mebendazole inhibited c-MYB protein expression in all cell lines examined, and RNA expression in some (Figure 3a). c-MYB protein expression was affected at lower concentrations of mebendazole than those required to inhibit RNA expression, and occurred without any change in RNA 
expression in some cells, suggesting that mebendazole targets c-MYB expression primarily at the protein level. Indeed, reversal of c-MYB protein loss by proteasomal inhibition indicates that mebendazole targets c-MYB for proteasomal degradation (Figure 3b and Supplementary Figure 5).

There has been considerable interest recently in repurposing mebendazole for cancer therapy. ${ }^{42}$ However, the mechanism for its anti-cancer activity has remained elusive. Initially this was thought to derive from its microtubule destabilizing activity, mebendazole binding tubulin at the colchicine-site, ${ }^{43}$ although recent experiments have suggested alternative mechanisms. ${ }^{44}$ We compared microtubule depolymerization and c-MYB degradation induced by mebendazole in AML cells to that resulting from treatment of the cells with the microtubule disrupting agent colcemid (Figure 4a and Supplementary Figure 6). Equivalent concentrations of colcemid induced both microtubule depolymerization and loss of c-MYB protein. In contrast, mebendazole induced c-MYB degradation at concentrations that do not cause microtubule depolymerization, indicating that the former is not a result of the latter per se.

Exactly how mebendazole induces c-MYB degradation is unclear. It does not appear to be a secondary consequence of a cell cycle block, since c-MYB loss is already evident in THP1 cells after 4 hours mebendazole exposure, prior to drug-induced changes in cell cycle profiles (Supplementary Figure 7). In order to address this question, nematic protein organisation technique (NPOT) analysis (Inoviem Scientific) of mebendazole was performed using cell lysates from a primary AML patient sample and THP1 cells (Supplementary Figures 8a and 8b). DAVID analysis of the proteins identified in the AML patient sample hetero-assemblies, induced by mebendazole, highlighted 'protein folding' as the second most significant functional category, with 12 of the 16 proteins in this category also identified in THP1 hetero-assemblies (Supplementary Figure 8c). This suggests that mebendazole disrupts the 
cellular protein folding machinery leading to the proteasomal targeting of c-MYB (Figure 3b). Of particular interest were a number of proteins of the HSP70/HSP90 chaperone complexes. c-MYB has previously been shown to be an HSC70 client protein in prostate cancer cells. $^{45,46}$ Indeed, we found that the HSP70/HSC70 chaperone complex is also associated with c-MYB in AML cells (Figure 4b and Supplementary Figure 9a), an association that was lost upon exposure to mebendazole (Figure 4c). Furthermore, HSPAlA knockdown and pharmacological HSP70 inhibition resulted in reduced c-MYB protein levels (Figure 4d and Supplementary Figure 9b and 9c). However, mebendazole did not induce any changes in expression levels or subcellular re-localization of the HSP70/HSC70 complex (Supplementary Figure 9d).

Since c-MYB has been placed at the center of a leukemia stem cell (LSC) transcriptional self-renewal program in $M L L$-rearranged leukemia, ${ }^{13}$ we hypothesized that mebendazole treatment of $M L L$-rearranged AML cells would inhibit this program. Indeed, GSEA analysis of gene expression changes following treatment of THP1 cells with mebendazole demonstrated negative enrichment of the LSC self-renewal signature (Figure 5a). In order to examine whether short-term exposure to mebendazole would indeed compromise AML cell self-renewal, we treated THP1 cells with $10 \mu \mathrm{M}$ mebendazole for 16 hours, washed them and examined their colony forming potential in vitro. Consistent with the observed inhibition of the LSC self-renewal program, transient exposure to mebendazole resulted in a more than $80 \%$ reduction in colony formation by THP1 cells (Figure $5 \mathrm{~b}$ ). Our hypothesis predicts that stabilization of the c-MYB protein would have the potential to rescue this loss of self-renewal induced by mebendazole. In order to examine this possibility, we generated a C-terminal deletion mutant of c-MYB ( $\triangle \mathrm{MYB})$, previously shown to result in enhanced protein stability, ${ }^{35}$ and expressed this mutant in THP1 cells. $\triangle \mathrm{MYB}$ was partially protected from mebendazole-induced degradation (Figure 5c). Since the mutant contained the unaltered 
DNA-binding domain, which is necessary for the transcriptional activity of c-MYB, but which contains residues known to be targeted by ubiquitin-mediated proteasomal degradation, ${ }^{47}$ it is not surprising that it was not completely resistant to mebendazole. However, $\triangle \mathrm{MYB}$ expressing THP1 cells were found to express higher levels of total c-MYB protein than control THP1 cells, following 6 hours treatment with mebendazole (Figure 5c). Importantly, this partial rescue of c-MYB protein expression correlated with increased colony forming potential of $\triangle \mathrm{MYB}$ expressing THP1 cells following transient exposure to mebendazole (Figure 5d). These data indicate that mebendazole inhibits AML colony formation by disrupting the c-MYB regulated LSC self-renewal program. Interestingly, transient mebendazole exposure also inhibited in vitro colony formation by two independent MLL-AF9 expressing primary AML patient samples, but had no significant effect on colony formation by normal $\mathrm{CD} 4^{+}$cord blood cells (Figure 5e and Supplementary Figure 10). Interestingly, mebendazole only caused partial loss of c-MYB in the latter (Supplementary Figure 11).

Having shown the anti-leukemia activity of mebendazole in vitro, we decided to test whether it could make an impact on AML disease progression in vivo. Oral administration of mebendazole, by simply mixing the drug in the diet, was found to have significant activity against disease in THP1 transplanted NSG mice, inhibiting leukemia progression (Figures 6a and b) and prolonging survival of treated mice (Figure 6c). Interestingly, THP-1 cells isolated from mebendazole-treated mice were found to express increased c-MYB protein levels and to be more resistant to drug treatment (Supplementary Figure 12). These data indicate that oral administration of mebendazole is sufficient to significantly impair AML progression in vivo. 
262 Our data show that mebendazole induces degradation of the transcription factor c-MYB. c263 MYB is essential for survival and self-renewal of multiple AML subtypes. c-MYB degradation results in loss of AML cell viability, colony formation and impaired in vivo leukemia progression. The rescue of AML cells from the inhibition of colony formation, following transient exposure to mebendazole, by over-expression of the $\Delta \mathrm{MYB}$ mutant highlights the significance of c-MYB degradation in the anti-AML effects of this drug. Although, the $\triangle \mathrm{MYB}$ mutant exhibits enhanced protein stability, ${ }^{35}$ it is not completely resistant to mebendazole induced degradation, potentially explaining why the rescue of colony formation is only partial. It is likely that mebendazole interferes with multiple pathways in cancer cells ${ }^{44}$ and it has been suggested to be a promising candidate for anticancer drug repurposing. ${ }^{42}$ However, the induction of c-MYB degradation by mebendazole makes it particularly suitable to repurposing into AML therapy.

Some solid cancers are also addicted to continued and relatively high expression of the oncoprotein c-MYB. This is particularly evident in colorectal cancer where c-MYB is overexpressed and essential to continued proliferation and tumor cell survival. ${ }^{19}$ In a recent study, mebendazole showed activity in the majority of the colon cancer cell lines tested. ${ }^{44}$ It is noteworthy that a patient with refractory metastatic colon cancer treated with mebendazole showed near complete remission of the metastases in the lungs and lymph nodes and a good partial remission in the liver. ${ }^{48}$ This suggests that mebendazole induced proteolysis of c-MYB may also have major clinical implications outside of AML therapy, in the treatment of a variety of cancers. and occurs at much lower concentrations than those necessary to achieve microtubule 
285 depolymerization in AML cells. We present evidence for the involvement of the 286 HSP70/HSC70 chaperone complex in c-MYB targeting by mebendazole. The complex was 287 found to bind c-MYB in AML cells, an association that was lost upon exposure of cells to 288 mebendazole. Pharmacological or shRNA directed inhibition of HSP70 also resulted in loss 289 of c-MYB protein. Interestingly, the HSP70/HSC70 complex has previously been shown to 290 interact with c-MYB in prostate cancer cells, its displacement form the complex by glioma 291 pathogenesis-related protein 1 (GLIPR1) over-expression resulting in c-MYB protein 292 destabilization. ${ }^{45,46}$

293 In summary, we have used Connectivity Map analysis to identify mebendazole as a novel 294 candidate anti-AML therapeutic. Our data highlight a hitherto unappreciated link between microtubule interacting agents and the regulation of c-MYB protein degradation. Importantly, widespread use of mebendazole is tolerated in children and adults across the world, ${ }^{49}$ suggesting that this drug has real potential for safe use in the treatment of human AML. 
300 The authors thank Ayad Eddaoudi and Stephanie Canning, UCL GOSICH Flow Cytometry

301 Facility, for providing assistance with flow cytometry, all staff of the UCL GOSICH Western

302 Laboratories for excellent animal husbandry, and Didier Trono for lentiviral packaging 303 constructs. JdB was supported by a fellowship from the Alternative Hair Charitable 304 Foundation and GOSH Children's Charity (W1073), and VW-V (W1003) and OW (V1305, 305 V2617) by grants from the GOSH Children's Charity. 


\section{REFERENCES}

3071 Pui CH, Carroll WL, Meshinchi S, Arceci RJ. Biology, risk stratification, and therapy 308 of pediatric acute leukemias: an update. J Clin Oncol 2011; 29: 551-565.

3092 Bose P, Vachhani P, Cortes JE. Treatment of Relapsed/Refractory Acute Myeloid $310 \quad$ Leukemia. Curr Treat Options Oncol 2017; 18: 17.

3113 Tasian SK, Pollard JA, Aplenc R. Molecular therapeutic approaches for pediatric $312 \quad$ acute myeloid leukemia. Front Oncol 2014; 4: 55.

3134 Khan M, Mansoor AE, Kadia TM. Future prospects of therapeutic clinical trials in $314 \quad$ acute myeloid leukemia. Future Oncol 2017; 13: 523-535.

3155 Meyer C, Hofmann J, Burmeister T, Groger D, Park TS, Emerenciano M, et al. The 316 MLL recombinome of acute leukemias in 2013. Leukemia 2013; 27: 2165-2176.

3176 Krivtsov AV, Armstrong SA. MLL translocations, histone modifications and 318 leukaemia stem-cell development. Nat Rev Cancer 2007; 7: 823-833.

3197 Slany RK. The molecular biology of mixed lineage leukemia. Haematologica 2009; 94: 984-993.

3218 Somervaille TC, Cleary ML. Grist for the MLL: how do MLL oncogenic fusion proteins generate leukemia stem cells? Int J Hematol 2010; 91: 735-741.

3239 Muntean AG, Hess JL. The pathogenesis of mixed-lineage leukemia. Annu Rev Pathol 2012; 7: 283-301.

32510 Neff T, Armstrong SA. Recent progress toward epigenetic therapies: the example of mixed lineage leukemia. Blood 2013; 121: 4847-4853. 
32711 Slany RK. The molecular mechanics of mixed lineage leukemia. Oncogene 2016; 35: $5215-5223$.

32912 Hess JL, Bittner CB, Zeisig DT, Bach C, Fuchs U, Borkhardt A, et al. c-Myb is an essential downstream target for homeobox-mediated transformation of hematopoietic cells. Blood 2006; 108: 297-304.

13 Somervaille TC, Matheny CJ, Spencer GJ, Iwasaki M, Rinn JL, Witten DM, et al. Hierarchical maintenance of MLL myeloid leukemia stem cells employs a transcriptional program shared with embryonic rather than adult stem cells. Cell Stem Cell 2009; 4: 129-140.

14 Jin S, Zhao H, Yi Y, Nakata Y, Kalota A, Gewirtz AM. c-Myb binds MLL through menin in human leukemia cells and is an important driver of MLL-associated leukemogenesis. J Clin Invest 2010; 120: 593-606.

15 Zuber J, Rappaport AR, Luo W, Wang E, Chen C, Vaseva AV, et al. An integrated approach to dissecting oncogene addiction implicates a Myb-coordinated self-renewal program as essential for leukemia maintenance. Genes Dev 2011; 25: 1628-1640. functional c-myb gene is required for normal murine fetal hepatic hematopoiesis. Cell occur in the absence of c-Myb whereas subsequent development is strictly dependent on the transcription factor. Oncogene 2000; 19: 3335-3342. 
34818 Lieu YK, Reddy EP. Conditional c-myb knockout in adult hematopoietic stem cells 349 leads to loss of self-renewal due to impaired proliferation and accelerated 350 differentiation. Proc Natl Acad Sci U S A 2009; 106: 21689-21694.

35119 Ramsay RG, Gonda TJ. MYB function in normal and cancer cells. Nat Rev Cancer 352 2008; 8: 523-534.

20 Pattabiraman DR, Gonda TJ. Role and potential for therapeutic targeting of MYB in leukemia. Leukemia 2013; 27: 269-277. encoded mRNA inhibits proliferation of human myeloid leukemia cell lines. Proc Natl Acad Sci U S A 1989; 86: 3379-3383. Normal and leukemic hematopoietic cells manifest differential sensitivity to inhibitory effects of c-myb antisense oligodeoxynucleotides: an in vitro study relevant

23 Gonda TJ, Ramsay RG. Directly targeting transcriptional dysregulation in cancer. Nat Rev Cancer 2015; 15: 686-694.

24 Emambokus N, Vegiopoulos A, Harman B, Jenkinson E, Anderson G, Frampton J. Progression through key stages of haemopoiesis is dependent on distinct threshold levels of c-Myb. EMBO J 2003; 22: 4478-4488. leukemia (AML) by human AML oncogenes. Blood 2014; 123: 2682-2690. 

Targeting acute myeloid leukemia with a small molecule inhibitor of the Myb/p300 interaction. Blood 2016; 127: 1173-1182.

27 Zhao L, Glazov EA, Pattabiraman DR, Al-Owaidi F, Zhang P, Brown MA, et al. Integrated genome-wide chromatin occupancy and expression analyses identify key

Osaki H, Walf-Vorderwulbecke V, Mangolini M, Zhao L, Horton SJ, Morrone G, et 
39333 Lamb J, Crawford ED, Peck D, Modell JW, Blat IC, Wrobel MJ, et al. The 394 Connectivity Map: using gene-expression signatures to connect small molecules, 395 genes, and disease. Science 2006; 313: 1929-1935.

39634 Williams G. SPIEDw: a searchable platform-independent expression database web tool. BMC Genomics 2013; 14: 765.

35 Corradini F, Cesi V, Bartella V, Pani E, Bussolari R, Candini O, et al. Enhanced 399 proliferative potential of hematopoietic cells expressing degradation-resistant c-Myb 400 mutants. J Biol Chem 2005; 280: 30254-30262.

401

36 Demaison C, Parsley K, Brouns G, Scherr M, Battmer K, Kinnon C, et al. High-level 402 transduction and gene expression in hematopoietic repopulating cells using a human immunodeficiency [correction of imunodeficiency] virus type 1-based lentiviral vector containing an internal spleen focus forming virus promoter. Hum Gene Ther 2002; 13: 803-813.

37 Minotti AM, Barlow SB, Cabral F. Resistance to antimitotic drugs in Chinese hamster ovary cells correlates with changes in the level of polymerized tubulin. J Biol Chem 1991; 266: 3987-3994. leukemogenesis. Blood 2008; 111: 4771-4779.

39 Soliera AR, Lidonnici MR, Ferrari-Amorotti G, Prisco M, Zhang Y, Martinez RV, et al. Transcriptional repression of c-Myb and GATA-2 is involved in the biologic 1950. 
40 Manzotti G, Mariani SA, Corradini F, Bussolari R, Cesi V, Vergalli J, et al.

417

418

419

420

421

422

423

424

425

426

427

428

429

430

431

432

433

434 Expression of p89(c-Mybex9b), an alternatively spliced form of c-Myb, is required for proliferation and survival of p210BCR/ABL-expressing cells. Blood Cancer J 2012; 2: e71.

41 Waldron T, De Dominici M, Soliera AR, Audia A, Iacobucci I, Lonetti A, et al. cMyb and its target Bmi1 are required for p190BCR/ABL leukemogenesis in mouse and human cells. Leukemia 2012; 26: 644-653.

42 Pantziarka P, Bouche G, Meheus L, Sukhatme V, Sukhatme VP. Repurposing Drugs in Oncology (ReDO)-mebendazole as an anti-cancer agent. Ecancermedicalscience 2014; 8: 443.

43 Laclette JP, Guerra G, Zetina C. Inhibition of tubulin polymerization by mebendazole. Biochem Biophys Res Commun 1980; 92: 417-423.

44 Nygren P, Fryknas M, Agerup B, Larsson R. Repositioning of the anthelmintic drug mebendazole for the treatment for colon cancer. J Cancer Res Clin Oncol 2013; 139: 2133-2140.

45 Li L, Yang G, Ren C, Tanimoto R, Hirayama T, Wang J, et al. Glioma pathogenesisrelated protein 1 induces prostate cancer cell death through Hsc70-mediated suppression of AURKA and TPX2. Mol Oncol 2013; 7: 484-496.

46 Liu W, Vielhauer GA, Holzbeierlein JM, Zhao H, Ghosh S, Brown D, et al. KU675, a Concomitant Heat-Shock Protein Inhibitor of Hsp90 and Hsc70 that Manifests Isoform Selectivity for Hsp90alpha in Prostate Cancer Cells. Mol Pharmacol 2015; 88: $121-130$. 
43847 Tanikawa J, Ichikawa-Iwata E, Kanei-Ishii C, Nakai A, Matsuzawa S, Reed JC, et al. p53 suppresses the c-Myb-induced activation of heat shock transcription factor 3. $J$ Biol Chem 2000; 275: 15578-15585.

$44148 \quad$ Nygren P, Larsson R. Drug repositioning from bench to bedside: tumour remission by 442 the antihelmintic drug mebendazole in refractory metastatic colon cancer. Acta Oncol 2014; 53: 427-428.

44449 Levecke B, Montresor A, Albonico M, Ame SM, Behnke JM, Bethony JM, et al. 445 Assessment of anthelmintic efficacy of mebendazole in school children in six countries where soil-transmitted helminths are endemic. PLoS Negl Trop Dis 2014; 8: e3204. 
450 Figure 1. Identification of mebendazole as a c-MYB targeting drug in AML. (a) Diagram 451 summarizing the generation of a c-MYB signature used to interrogate the CMAP database ${ }^{33}$ using SPIEDw ${ }^{34}$. (b) The 1,309 CMAP drugs are ranked based on the significance of regression scores between their transcriptional profiles and that of the query. The Z-score corresponds to the number of standard deviations of the score away from the mean. Inset is the structure of mebendazole (rank 1). (c) GSEA of the c-MYB activated (top) and repressed (bottom) gene sets in global gene expression changes in THP1 cells following 6 hours exposure to $10 \mu \mathrm{M}$ mebendazole (MBZ) versus DMSO.

Figure 2. Mebendazole inhibits AML growth and colony formation. (a) Viability, normalized to DMSO controls, of AML cell lines treated for 72 hours with indicated mebendazole concentrations. Bars and error bars are means and SD of three independent experiments, each in triplicate. (b) Examples of AML cell line colony formation in methylcellulose cultures in the presence of DMSO or $1.25 \mu \mathrm{M}$ mebendazole (quantification in Supplementary Figure 1).

Figure 3. Mebendazole induces proteasomal degradation of c-MYB. (a) Protein and RNA expression in AML cells after 6 hours treatment with DMSO or indicated mebendazole concentrations, normalized to DMSO controls. Bars and error bars are means and SD of three independent experiments. ${ }^{*} P<0.05$; $* * P<0.01$; $* * * P<0.001$; n.s. not significant (relative to DMSO controls), one sample $t$ test. Western blots below graphs show examples of c-MYB protein expression. (b) Western blot analysis of c-MYB protein expression in AML cells after 6 hours treatment with DMSO, $10 \mu \mathrm{M}$ mebendazole or $10 \mu \mathrm{M}$ mebendazole and $10 \mu \mathrm{M}$ MG132 (quantification in Supplementary Figure 3).

Figure 4. Mebendazole destabilizes c-MYB protein by interfering with the HSP70/HSC70 chaperone pathway. (a) Percent polymerized tubulin in THP1 cells following 6 hours 
treatment with indicated concentrations of mebendazole (top left) or colcemid (top right), and western blot analysis of corresponding c-MYB protein expression (bottom). Tubulin stabilization by $5 \mu \mathrm{M}$ paclitaxel (Pax) is also shown. Bars and error bars are means and SD of three independent experiments. ${ }^{*} P<0.05$; $* * P<0.01$; $* * * P<0.001$; n.s. not significant, unpaired Student's t-test. (b) Western blot analysis of mouse IgG and anti-HSP70/HSC70 immunoprecipitates from THP1 cells, stained with anti-c-MYB (top) and anti-HSP70/HSC70 (bottom). Representative data from one of three independent experiments. (c) Western blot analysis of anti-HSP70/HSC70 immunoprecipitates from THP1 cells following 6 hours treatment with DMSO or $10 \mu \mathrm{M}$ mebendazole, stained with anti-c-MYB (top) and antiHSP70/HSC70 (bottom). Representative data from one of three independent experiments. (d) Western blot analysis of HSP70 (top) and c-MYB (middle) expression in THP1 cells 7 days after transduction with control scramble (shSCR) shRNA or two independent shRNA targeting HSPA1A (sh1 and sh2) (quantification in Supplementary Figure 7b).

Figure 5. Transient exposure to mebendazole inhibits colony formation by AML but not normal cord blood-derived hematopoietic cells. (a) GSEA of the gene expression signatures positively (top) and negatively (bottom) correlating with leukemia stem cell frequency ${ }^{13}$ in global gene expression changes in THP1 cells following 6 hours exposure to $10 \mu \mathrm{M}$ mebendazole versus DMSO. (b) Example of THP1 colony formation after pre-treatment with DMSO or $10 \mu \mathrm{M}$ mebendazole. Cells were treated with vehicle or drug for 16 hours, washed and placed into methylcellulose culture. The mean $( \pm$ SD) fold change in colony formation is shown from five independent experiments, normalized to DMSO controls. $* * * P<0.001$ (relative to DMSO controls), one sample $t$ test. (c) c-MYB protein expression in empty vector (Con) or c-MYB deletion mutant $(\triangle \mathrm{MYB})$ transduced THP1 cells, 6 hours after treatment with DMSO or $10 \mu \mathrm{M}$ mebendazole. (d) Fold change in colony formation by Con or $\triangle \mathrm{MYB}$ transduced THP1 cells, following 16 hours pre-treatment with DMSO or $10 \mu \mathrm{M}$ 
mebendazole, normalized to Con or $\triangle \mathrm{MYB}$ DMSO controls. Bars and error bars are means and SD of seven independent experiments. $* * * P<0.001$, unpaired Student's t-test. (e)

500 Colony formation frequency by two independent primary AML patient samples (AML1547, 501 AML1497) and two independent normal CD34 ${ }^{+}$cord blood samples (CB1, CB2) after pre502 treatment with DMSO or $10 \mu \mathrm{M}$ mebendazole. Cells were treated with vehicle or drug for 20 hours, washed and placed into methylcellulose culture.

504 Figure 6. Mebendazole impairs AML progression in vivo. (a) Bioluminescence imaging of NSG recipient mice 10 days after injection with THP1-LUC2 cells, and before drug treatment, (day 0 , top), and 22 days after treatment with normal or mebendazole-containing

507 diet (bottom). Bars for luminescence signal represent photons $/ \mathrm{s} / \mathrm{cm}^{2} / \mathrm{steradian}$.

508 Luminescence signal in treatment groups, 10 days after THP1-LUC2 cell injection and before 509 drug treatment (left), and fold increase in luminescence signal in the groups 7 and 17 days 510 after treatment with normal or mebendazole-containing diet (right). Bars and error bars are 511 means and SD of values form control $(\mathrm{n}=5)$ and mebendazole-treated $(\mathrm{n}=9)$ groups. $* * * P<$ 512 0.001; n.s. not significant, unpaired Student's t-test. (c) Survival curve for control $(\mathrm{n}=9)$ and mebendazole-treated $(\mathrm{n}=12)$ mice, $P<0.0001$, Mantel-Haenszel log-rank test. 
a

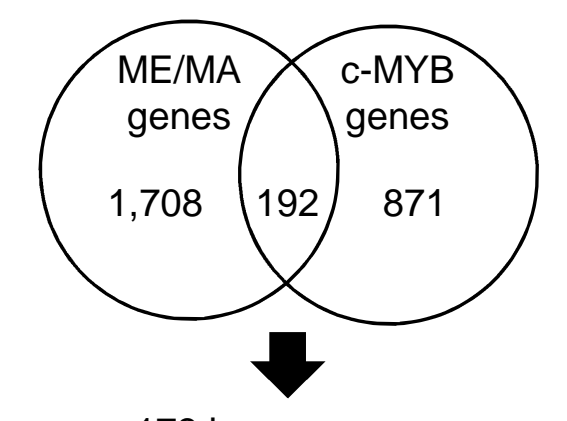

173 human genes

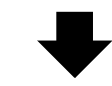

SPIEDW

(CMAP drug dataset)

C

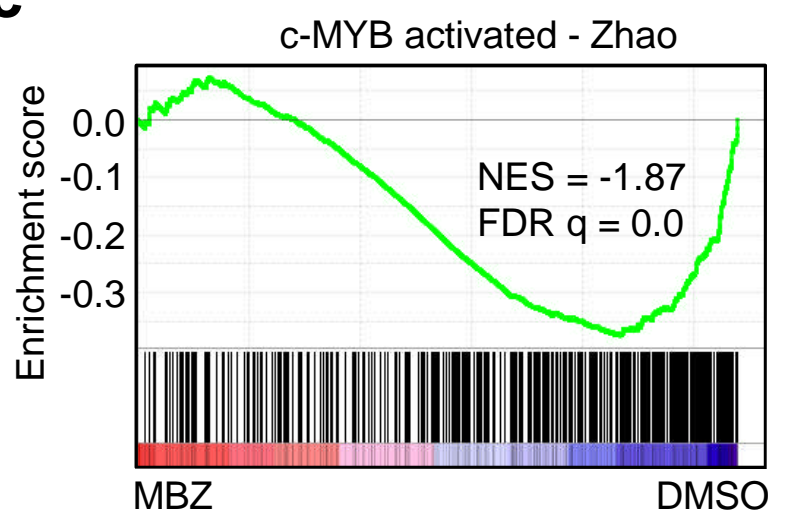

b

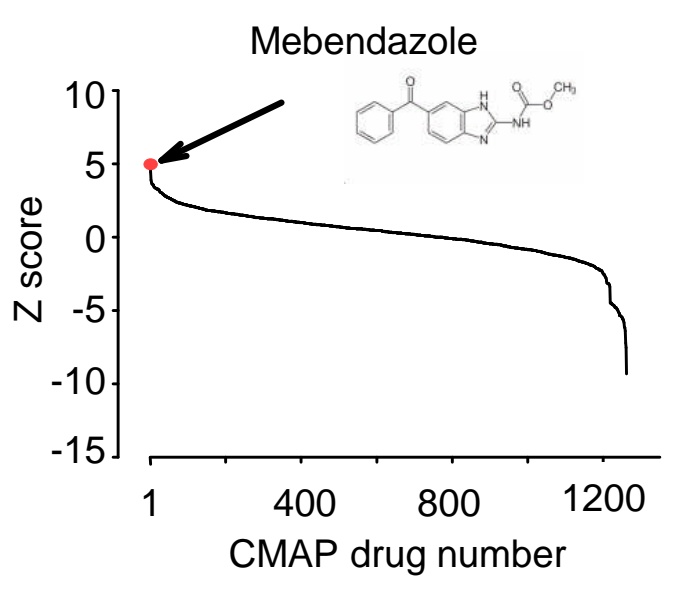

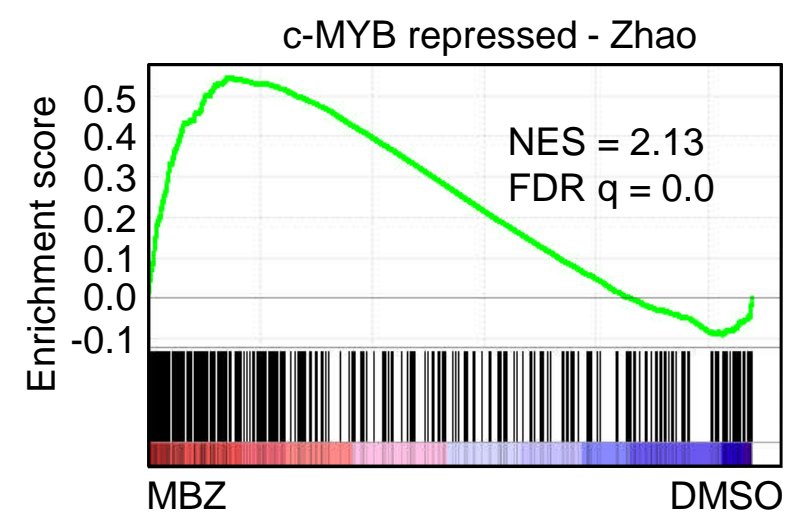

\section{FIGURE 1}


a

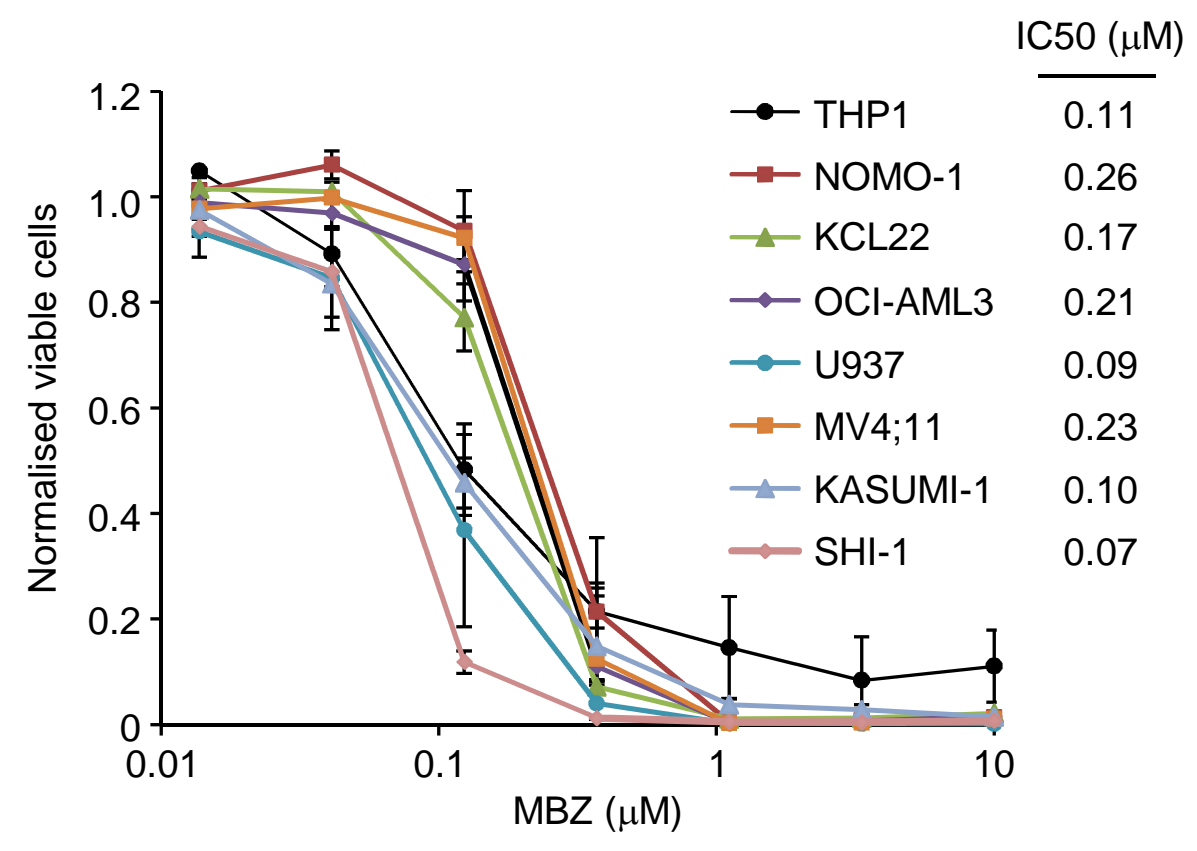

b

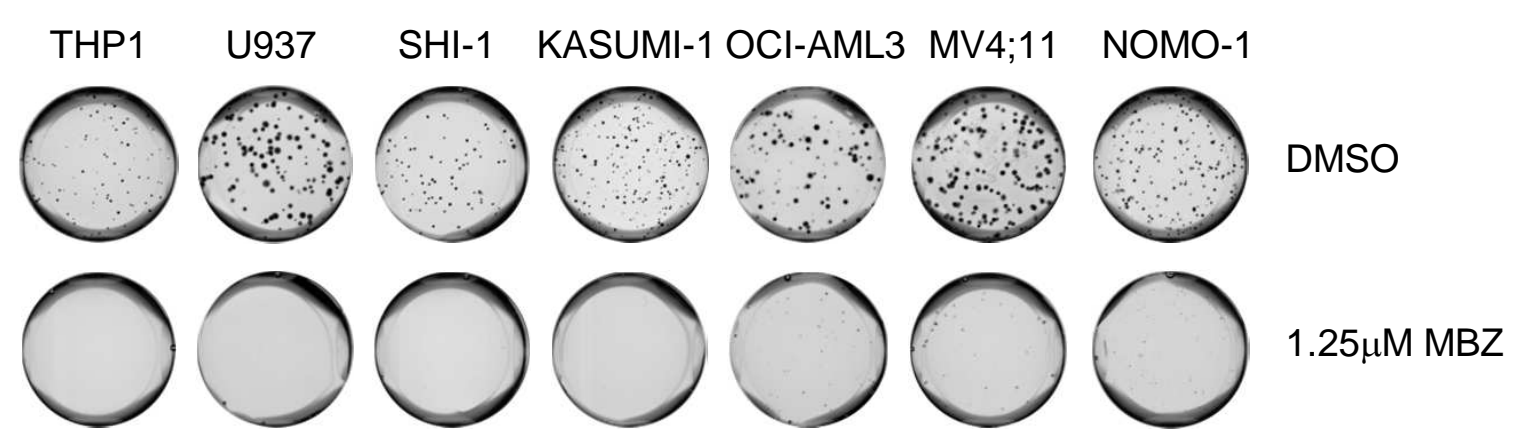

FIGURE 2 


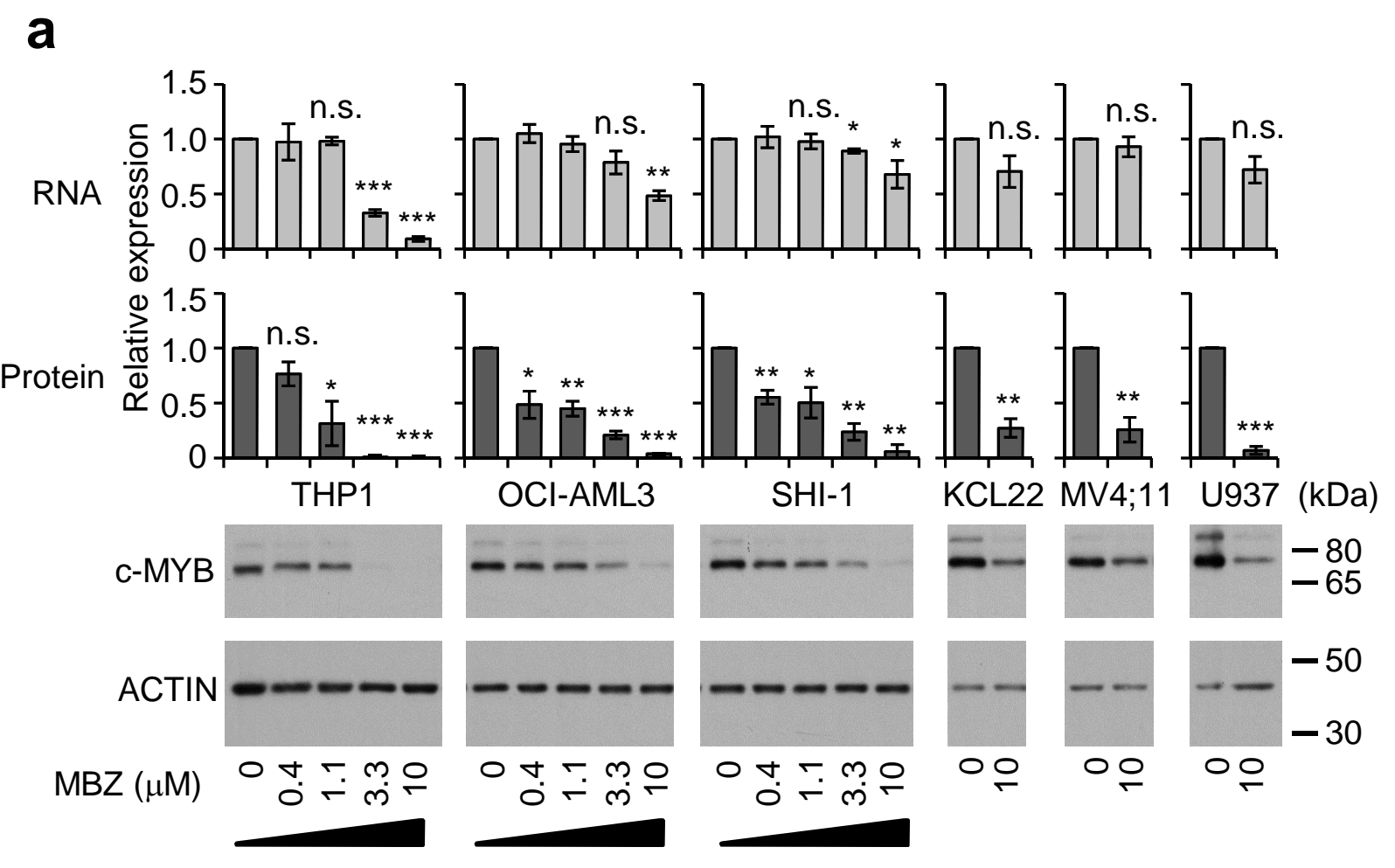

b

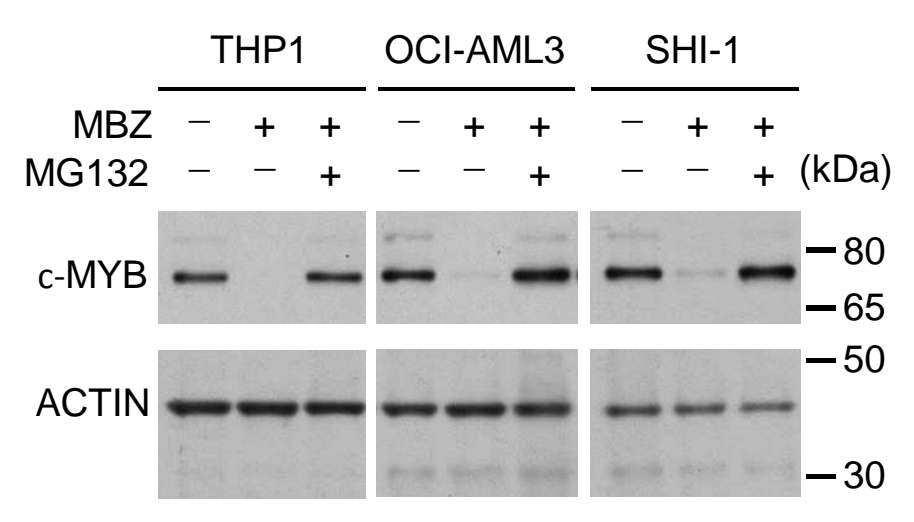

FIGURE 3 
a
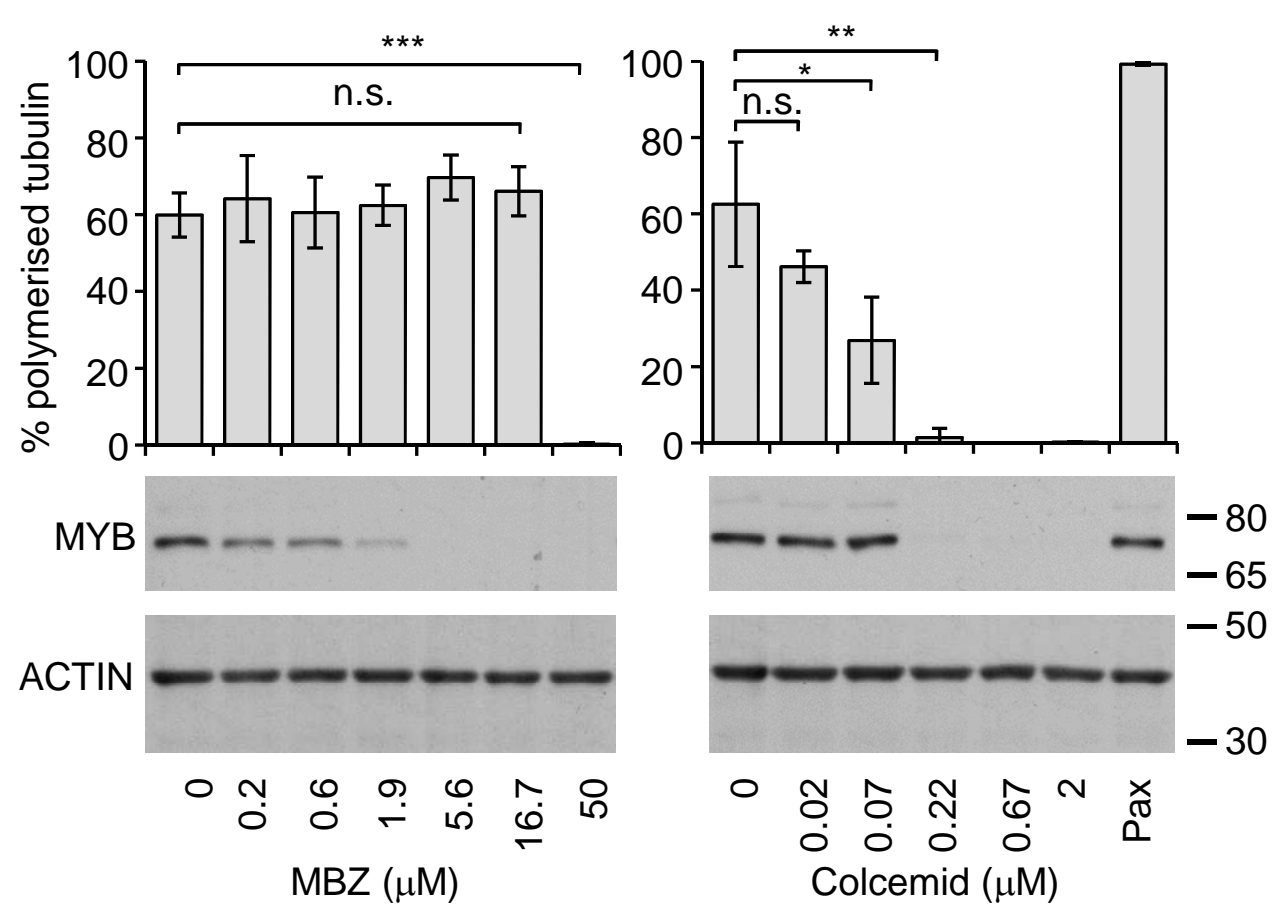

b

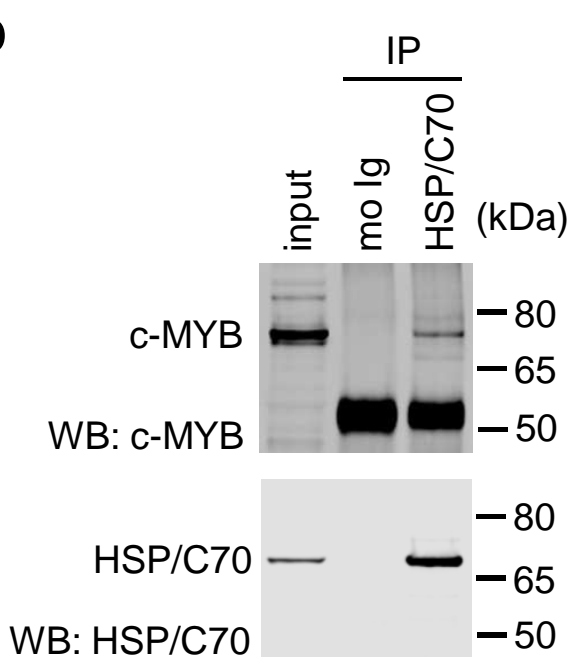

C

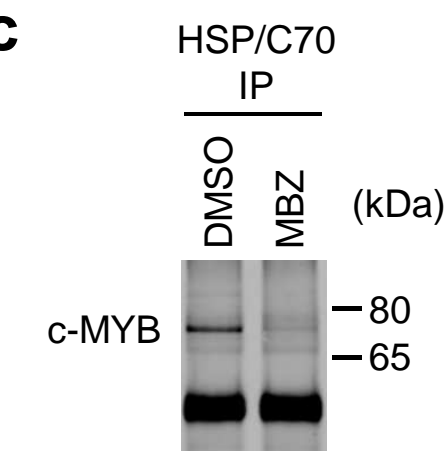

HSP/C70 - -80 d

HSPA1A

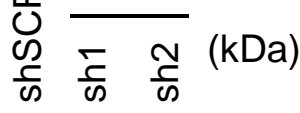

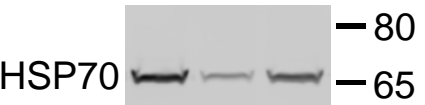

$-50$

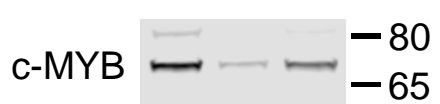

$-50$

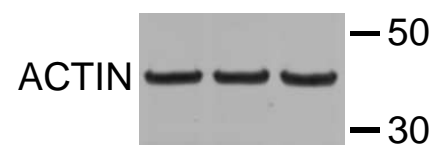


a

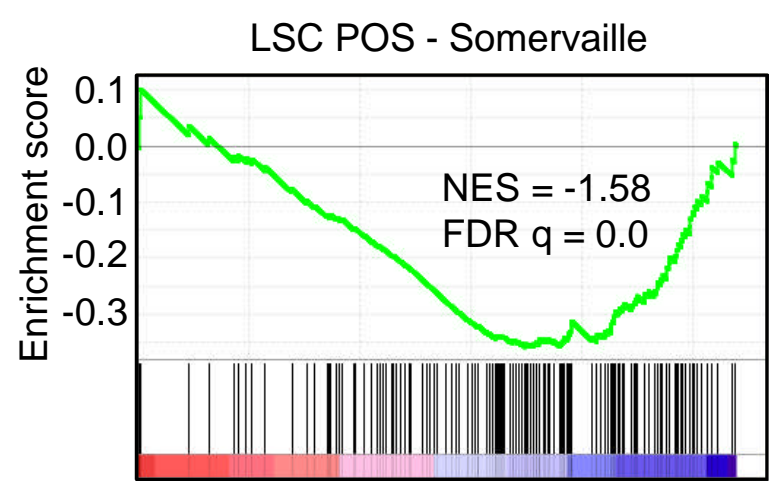

LSC NEG - Somervaille

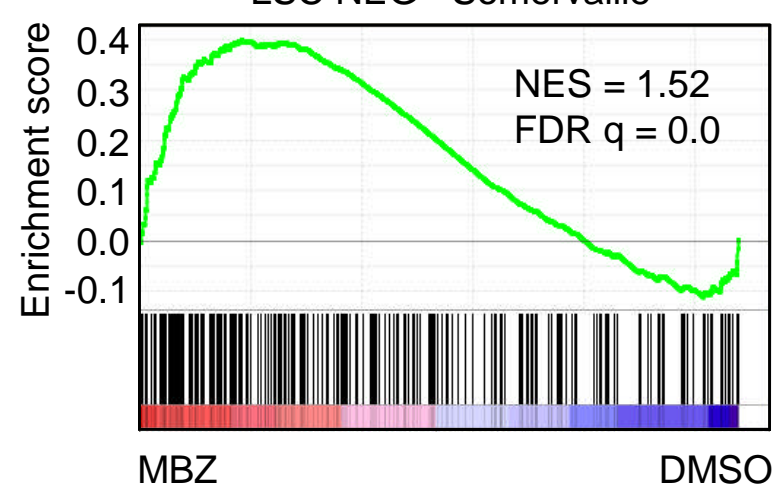

b

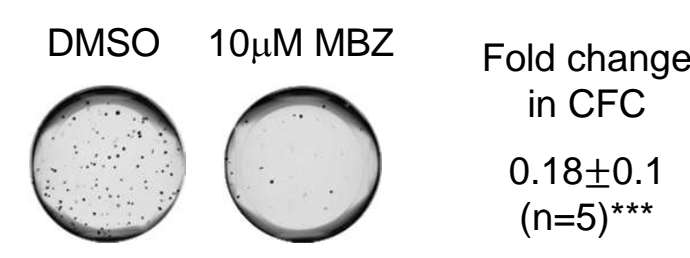

C

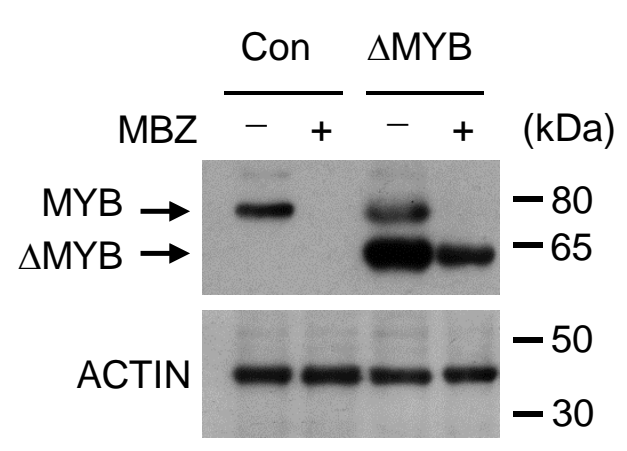

e
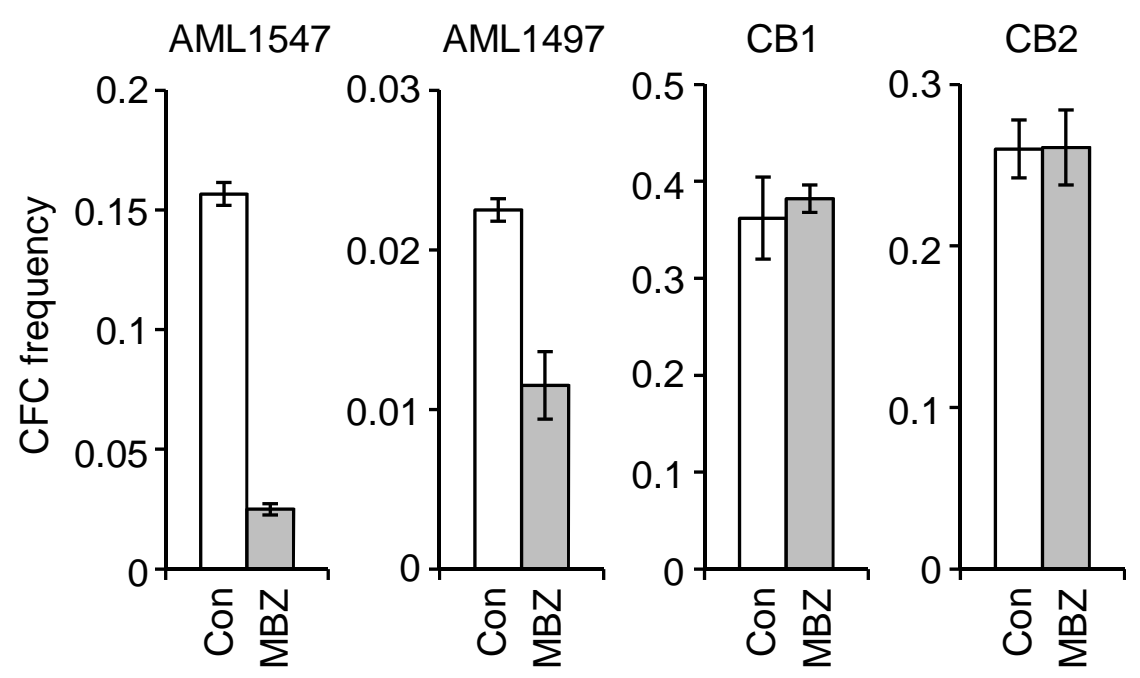

FIGURE 5 


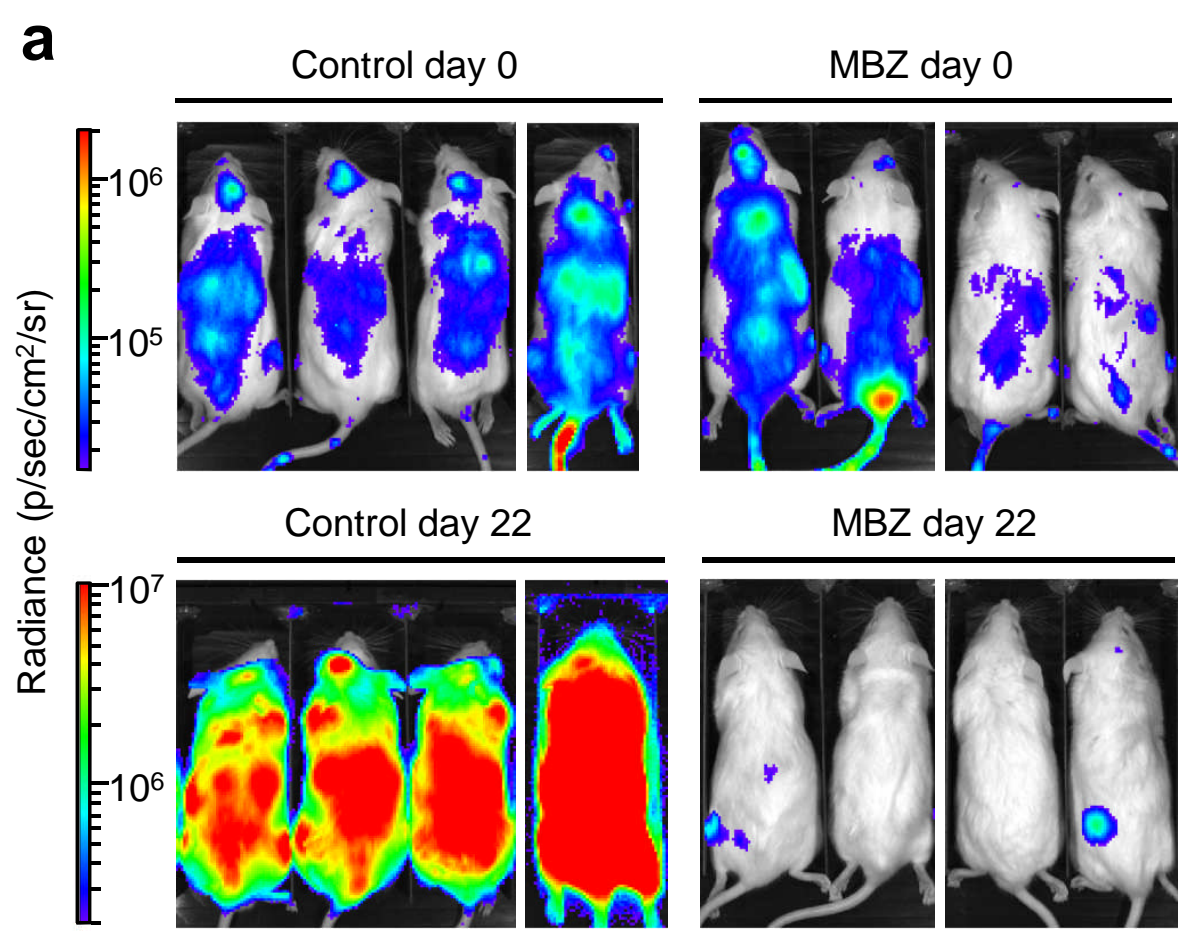

b
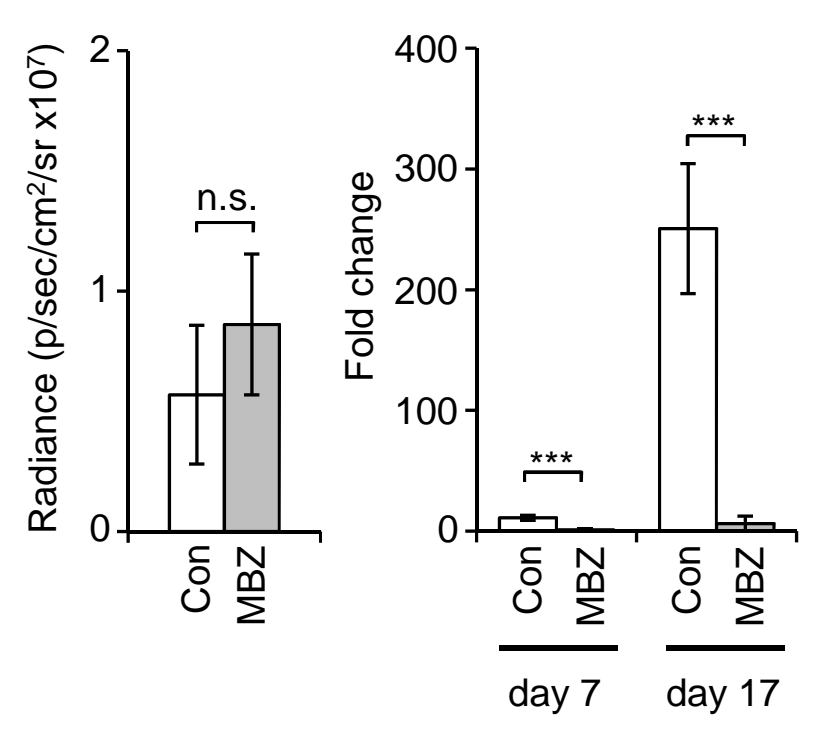

C

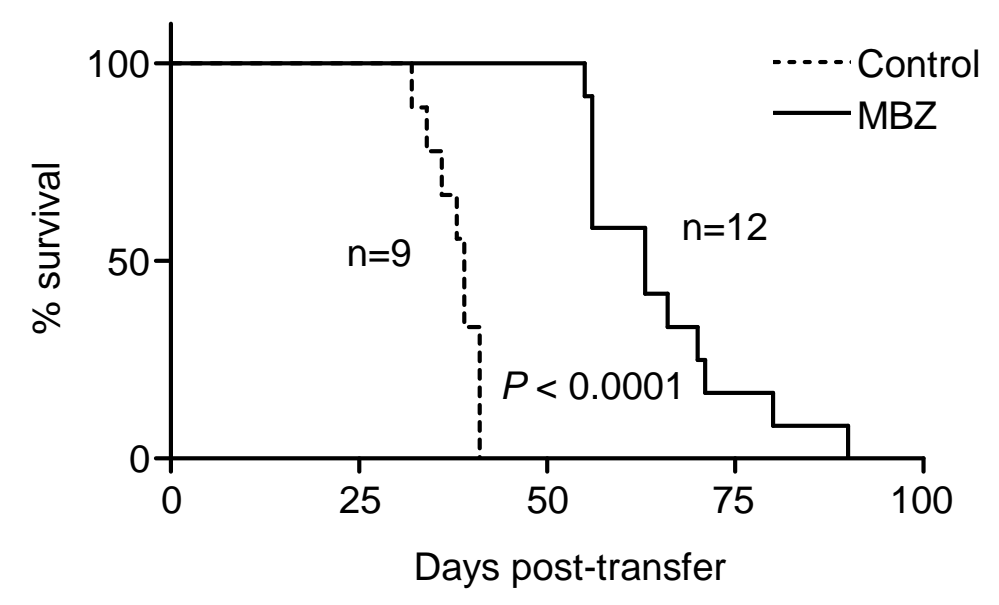

FIGURE 6 


\section{SUPPLEMENTARY MATERIALS AND METHODS}

Mice

All mice were maintained in the animal facilities of the UCL Great Ormond Street Institute of Child Health, London. All mouse experiments were performed according to and approved by the United Kingdom Home Office regulations and followed UCL Great Ormond Street Institute of Child Health institutional guidelines.

Human samples

Primary AML mononuclear cells were isolated by sucrose gradient centrifugation (Lymphoprep, 1.077 g/ml density; Nycomed Pharma).

Global gene expression analysis

Conditionally immortalized MLL-ENL and MLL-AF9 mouse myeloid cells have been previously described. ${ }^{1-4}$ Control constitutive and conditionally immortalized cells were treated with $2 \mu \mathrm{g} / \mathrm{ml}$ doxycycline for 48 hours, RNA extracted using TRIzol reagent (ThermoFisher Scientific) and quality verified using an Agilent 2100 Bioanalyzer (Agilent Technologies, Wokingham, UK). RNA was hybridized to GeneChip Mouse Genome 430.2 arrays (Affymetrix). Data was analyzed using GeneSpring 7.3.1 software (Agilent Technologies). Gene expression changes of more than 2 -fold, with a defined $P$-value cut-off $\leq 0.05$, upon treatment with doxycycline were selected. Genes whose expression changed more than 2-fold in constitutive cells, upon doxycycline treatment, were excluded. Duplicate probe sets were removed, keeping those with the highest fold change. THP1 cells were cultured at $0.5 \times 10^{6}$ cells $/ \mathrm{ml}$ and treated with $10 \mu \mathrm{M}$ mebendazole or DMSO control, for 6 hours. RNA was purified and submitted to UCL Genomics for RNA-sequencing. Samples were processed using an Illumina TruSeq RNA sample prep kit Version 2 (RS-122-2001) 
according to manufacturer's instructions (Illumina, Cambridge, UK) and sequenced on an Illumina NextSeq 500 (Illumina). Differential expression was obtained using the RNA Express BaseSpace® app (Illumina). Low expressed genes were removed from the output file. This was used for GSEA analysis.

Gene expression changes for SPIEDw analysis

MLL-ENL/MLL-AF9 gene expression changes, for genes also contained in the list of 1063 genes bound by c-MYB in mouse myeloid ERMYB cells ${ }^{5}$ and deregulated in THP1 cells following siRNA-mediated c-MYB silencing, ${ }^{6}$ were selected. These genes were converted into human gene names using the HGNC Comparison of Orthology Predictions (HCOP) search tool, ${ }^{7}$ using the HGNC orthologs. This list (Supplementary Table 2) was then used to interrogate the CMAP database (https://portals.broadinstitute.org/cmap/) ${ }^{8}$ using the SPIEDw web tool $^{9}$ (http://www.spied.org.uk/), which allows queries to be entered as gene names rather than probe sets.

Gene set enrichment analysis

c-MYB signatures ${ }^{5}$ were genes bound by c-MYB in mouse myeloid ERMYB cells and deregulated in THP1 cells following siRNA-mediated c-MYB silencing, ${ }^{6}$ either decreasing in expression (MYB activated) or increasing in expression more than 1.5-fold (MYB repressed). LSC signatures ${ }^{10}$ consisted of probe sets positively correlated with LSC frequency (LSC POS) and negatively correlated with LSC frequency (LSC NEG). Mouse gene names were converted into human gene names using the HCOP using the HGNC orthologs, as above.

Cell culture and reagents 
Human AML cell lines were cultured in RPMI or IMDM (SHI-1) supplemented with 1020\% FCS, L-glutamine and penicillin/streptomycin. 293FT (ThermoFisher Scientific) cells were maintained in DMEM with 10\% FCS, L-glutamine, penicillin/streptomycin and 500 $\mu \mathrm{g} / \mathrm{ml}$ G418. For some experiments, $\mathrm{CD} 4^{+}$cord blood-derived cells (ZenBio) were expanded in StemSpan SFEM II medium (StemCell Technologies, Grenoble, France) supplemented with $100 \mathrm{ng} / \mathrm{ml}$ human SCF, TPO and FLT3L (all from Peprotech, London, UK).

Colony formation assays

AML cell lines were plated out in HSC002 methylcellulose medium (Bio Techne) at 150-500 cells/well in 24-well plates. Colonies were grown for 7-14 days and visualized by staining with $1 \mathrm{mg} / \mathrm{ml}$ p-iodonitrotetrazolium. For pre-stimulation, primary AML cells and normal $\mathrm{CD} 4^{+}$cord blood-derived cells (ZenBio) were cultured with DMSO or $10 \mu \mathrm{M}$ mebendazole for 20 hours in IMDM with 10\% FCS, L-glutamine, penicillin/streptomycin. AML cells were supplemented with $100 \mathrm{ng} / \mathrm{ml}$ human SCF, TPO and FLT3L, $10 \mathrm{ng} / \mathrm{ml}$ IL3, IL6 and IL11, and $\mathrm{CD}_{3} 4^{+}$cord blood-derived cells with $100 \mathrm{ng} / \mathrm{ml}$ human SCF, TPO and FLT3L (all growth factors were form Peprotech). Cells were plated out into HSC005 methylcellulose medium (Bio Techne) containing $50 \mathrm{ng} / \mathrm{ml}$ human SCF, $20 \mathrm{ng} / \mathrm{ml}$ IL3, IL6, G-CSFD, GMCSF and $3 \mathrm{IU} / \mathrm{ml}$ EPO at 300-1000 cells/well in $35 \mathrm{~mm}$ plates. Primary AML methylcellulose cultures were further supplemented with $50 \mathrm{ng} / \mathrm{ml}$ TPO and FLT3L. Cultures were counted and morphology scored 14 days later.

Growth, apoptosis and cell cycle assays

The effect of mebendazole on growth of AML cell lines was examined by exposing them to different concentrations of mebendazole in liquid culture, starting at $1.25-2.5 \times 10^{5}$ cells $/ \mathrm{ml}$, 
and 72 hours later were stained with TO-PRO®-3 (ThermoFisher Scientific) stain and total viable cells were determined by flow cytometry analysis on a BD FACSArray ${ }^{\mathrm{TM}}$ Bioanalyzer, using Summit 4.3 software (Beckman Coulter, High Wycombe, UK). Apoptosis was detected using the Annexin V Apoptosis detection kit (eBioscience, Hatfield, UK). Cell cycle analysis was performed using the Click-iT EdU Alexa Flour 647 Flow Cytometry Assay Kit (Invitrogen, Life Technologies). Cells were analyzed on an LSRII (BD Bioscience, San Jose, CA, USA), and the data were analyzed with Summit 4.3 software (Beckman Coulter).

Nematic protein organisation technique (NPOT) analysis

NPOT is a label free proprietary technology offered by INOVIEM Scientific, used to isolate and identify specific macromolecular scaffolds implemented in basic or pathological situations directly from human tissue. Specifically, primary AML sample AML4298 and THP1 cell homogenates were prepared under low temperature $\left(4^{\circ} \mathrm{C}\right)$ in the absence of any detergent, reducing agent or protease or phosphatase inhibitors. All dilutions and washes were performed in HBSS with osmolality, trace elements, vitamins and salts concentrations as close as possible to those of the interstitial medium or cellular cytoplasm. Mebendazole $(1 \mu \mathrm{M})$ was added to the total tissue material. The macromolecular assemblies related to the specific ligands were then separated using a differential microdialysis system, based on liquid transitory $\mathrm{pH}$ gradient ( $\mathrm{pH} 5-10)$ where the macromolecules (protein groups) can migrate in the liquid phase to their mean molecular zwitterion positions. ${ }^{11-14}$ The gradually growing and migrating macromolecules will form nematic crystals to macromolecular hetero-assemblies thanks to the molecular interactions between the ligand(s) and their targets. The heteroassemblies are then trapped in mineral oil and isolated and identified by mass spectroscopy directly in liquid. Formation of hetero-assemblies and crystals were induced by addition of mebendazole and did not form in its absence. 
In vivo transplantation

THP1 cells were transduced with a lentivirus vector containing a luciferase (LUC2)-IRESEGFP cassette, and $\mathrm{EGFP}^{+}$cells purified by flow cytometric sorting. 1-2 x $10^{6}$ THP1-LUC2 cells were transplanted into non-irradiated 6-12 week old male NOD-SCID- $\gamma^{-/-}$(NSG; The Jackson Laboratory) mice by lateral tail vein injection. Recipient mice were imaged 10 minutes following subcutaneous injection of $5 \mathrm{mg} / \mathrm{mouse}$ D-luciferin (Cayman Chemical Company, Ann Arbor, MI, USA) using the IVIS® Lumina Series III pre-clinical in vivo imaging system (PerkinElmer) and randomly allocated to control or mebendazole-treated groups by flipping a coin. Mebendazole (200 mg/kg of diet) was administered ad libitum in regular powdered diet, changed daily. Group sizes were chosen based on previous estimates of disease latency in THP1 transplanted mice and experiments in the literature performing similar studies. No mice were excluded from the analysis. No blinding was used in group allocation or analysis of data.

Lentivirus vector cloning, production and transduction of cell lines The $\triangle \mathrm{MYB} \mathrm{cDNA}^{15}$ was cloned into the $\mathrm{pCSGW}-\mathrm{PIG}$ vector, made by replacing the GFP cDNA from $\mathrm{pCSGW}^{16}$ with a puro-IRES-GFP cassette, and the resulting vector used to transduce THP1 cells. The luciferase (LUC2) cDNA was cloned into pCSGW. Lentiviral MISSION shRNA constructs targeting c-MYB (Clone ID:NM_005375.2-927s21c1), HSPA1A (sh1:Clone ID:NM_005345.4-1539s1c1; sh2:Clone ID:NM_005345.4-566s1c1) and the scramble (SCR) non-silencing control (SHC002) were purchased from SigmaAldrich. The 293FT packaging cells (ThermoFisher Scientific) were transiently cotransfected with the lentiviral expression vectors, the pCMV-PAX2 construct and the pVSV-G envelope construct (kind gifts of D. Trono, Lausanne, Switzerland). Human leukemia cells were 
transduced with lentiviral supernatant by spinoculation at $700 \mathrm{~g}, 25^{\circ} \mathrm{C}$ for 45 minutes in the presence of $5 \mu \mathrm{g} / \mathrm{mL}$ polybrene. Transduced cells were selected in puromycin for 72 hours.

Western blot analysis

Cells were lysed in reducing sample buffer (100 mM dithiothreitol, 2\% sodium dodecyl sulfate, $10 \%$ glycerol, $0.002 \%$ bromophenol blue, $62.5 \mathrm{mM}$ Tris-HCL pH 6.8). Nuclear and cytoplasmic lysates were prepared using the Nuclear Extract kit (Active Motif, La Hulpe, Belgium). Protein samples were resolved on gels $10 \%$ polyacrylamide $(0.36 \mathrm{M}$ bis-Tris, 10 $\%$ acrylamide/bis) in MOPS-SDS running buffer (50 mM Tris, $50 \mathrm{mM}$ MOPS, $1 \mathrm{mM}$ EDTA, $0.1 \%$ SDS). Gels were transferred onto a PVDF (Merck Millipore) or nitrocellulose (LICOR Biosciences, Cambridge, UK) membranes. Proteins were detected using appropriate secondary horseradish peroxidase-conjugated antibodies and visualized using a chemiluminescence reagent (GE Healthcare, Little Chalfont, UK) or IRDye 800CW and IRDye 680RD labelled secondary antibodies (LI-COR Biosciences). Quantification was performed on scanned unsaturated bands using the GS800 Imaging densitometer and Quantity One software (Bio-Rad Laboratories, Hemel Hempstead, UK) or on fluorescent images using the Odyssey® CLx and Image Studio software (LI-COR Biosciences).

\section{Microtubule depolymerization assay}

AML cells were treated for 6 hours with mebendazole, colcemid (ThermoFisher Scientific) or paclitaxel (Cayman Chemical Company). 1 x $10^{6}$ cells were washed twice in PBS and resuspended in $100 \mu \mathrm{l}$ depolymerization buffer (20mM Tris- $\mathrm{HCl} \mathrm{pH} 6.8,0.14 \mathrm{M} \mathrm{NaCl}, 0.5 \%$ NP-40, $1 \mathrm{mM} \mathrm{MgCl} 2,2$ mM EGTA, $10 \mu \mathrm{M}$ paclitaxel, protease inhibitors) ${ }^{17}$ and vortexed on maximum setting. Lysis of cells with this microtubule-stabilizing buffer preserves the proportions of polymerized and soluble microtubules present in vivo in cells, following the 
period of drug treatment. Cells were then centrifuged at $12,000 \mathrm{x} g$ for $10 \mathrm{~min}$ at $4^{0} \mathrm{C}$. The supernatant was decanted and $100 \mu \mathrm{l} 2 \mathrm{x}$ reducing sample buffer added (S, soluble tubulin). The pellet was resuspended in $100 \mu 1 \mathrm{mM} \mathrm{CaCl}$ (with protease inhibitors), incubated at room temperature for 15 minutes, with brief vortexing and $100 \mu \mathrm{l} 2 \mathrm{x}$ reducing sample buffer added ( $\mathrm{P}$, lysate pellet). Percent polymerized tubulin was calculated from the formula $\mathrm{P} /(\mathrm{P}+$ S)100 from quantified western blot bands.

Quantitative RT-PCR analysis

Total RNA was isolated from cells using RNeasy Mini Kit (Qiagen, Manchester, UK) according to the manufacturer's instructions. RNA was converted into cDNA using a cDNA synthesis kit (Invitrogen, Life Technologies) according to the manufacturer's instructions. Samples were treated with DNase I (Invitrogen, Life Technologies) prior to reverse transcription using the Moloney murine leukemia virus reverse transcriptase (Invitrogen, Life Technologies). 


\section{SUPPLEMENTARY REFERENCES}

1 Horton SJ, Grier DG, McGonigle GJ, Thompson A, Morrow M, De Silva I, et al. Continuous MLL-ENL expression is necessary to establish a "Hox Code" and maintain immortalization of hematopoietic progenitor cells. Cancer Res 2005; 65: 9245-9252.

2 Horton SJ, Walf-Vorderwulbecke V, Chatters SJ, Sebire NJ, de Boer J, Williams O. Acute myeloid leukemia induced by MLL-ENL is cured by oncogene ablation despite acquisition of complex genetic abnormalities. Blood 2009; 113: 4922-4929.

3 Walf-Vorderwulbecke V, de Boer J, Horton SJ, van Amerongen R, Proost N, Berns A, et al. Frat2 mediates the oncogenic activation of Rac by MLL fusions. Blood 2012; 120: 4819-4828.

4 Osaki H, Walf-Vorderwulbecke V, Mangolini M, Zhao L, Horton SJ, Morrone G, et al. The AAA+ ATPase RUVBL2 is a critical mediator of MLL-AF9 oncogenesis. Leukemia 2013; 27: 1461-1468.

5 Zhao L, Glazov EA, Pattabiraman DR, Al-Owaidi F, Zhang P, Brown MA, et al. Integrated genome-wide chromatin occupancy and expression analyses identify key myeloid pro-differentiation transcription factors repressed by Myb. Nucleic Acids Res 2011; 39: 4664-4679.

6 Suzuki H, Forrest AR, van Nimwegen E, Daub CO, Balwierz PJ, Irvine KM, et al. The transcriptional network that controls growth arrest and differentiation in a human myeloid leukemia cell line. Nat Genet 2009; 41: 553-562. 
7 Eyre TA, Wright MW, Lush MJ, Bruford EA. HCOP: a searchable database of human orthology predictions. Brief Bioinform 2007; 8: 2-5.

8 Lamb J, Crawford ED, Peck D, Modell JW, Blat IC, Wrobel MJ, et al. The Connectivity Map: using gene-expression signatures to connect small molecules, genes, and disease. Science 2006; 313: 1929-1935.

9 Williams G. SPIEDw: a searchable platform-independent expression database web tool. BMC Genomics 2013; 14: 765.

10 Somervaille TC, Matheny CJ, Spencer GJ, Iwasaki M, Rinn JL, Witten DM, et al. Hierarchical maintenance of MLL myeloid leukemia stem cells employs a transcriptional program shared with embryonic rather than adult stem cells. Cell Stem Cell 2009; 4: 129-140.

11 Bolen DW, Baskakov IV. The osmophobic effect: natural selection of a thermodynamic force in protein folding. J Mol Biol 2001; 310: 955-963.

12 Shimizu S. Estimating hydration changes upon biomolecular reactions from osmotic stress, high pressure, and preferential hydration experiments. Proc Natl Acad Sci U S A 2004; 101: 1195-1199.

13 Zhou HX, Rivas G, Minton AP. Macromolecular crowding and confinement: biochemical, biophysical, and potential physiological consequences. Annu Rev Biophys 2008; 37: 375-397.

14 Gee MB, Smith PE. Kirkwood-Buff theory of molecular and protein association, aggregation, and cellular crowding. J Chem Phys 2009; 131: 165101. 
15 Corradini F, Cesi V, Bartella V, Pani E, Bussolari R, Candini O, et al. Enhanced proliferative potential of hematopoietic cells expressing degradation-resistant c-Myb mutants. J Biol Chem 2005; 280: 30254-30262.

16 Demaison C, Parsley K, Brouns G, Scherr M, Battmer K, Kinnon C, et al. High-level transduction and gene expression in hematopoietic repopulating cells using a human immunodeficiency [correction of imunodeficiency] virus type 1-based lentiviral vector containing an internal spleen focus forming virus promoter. Hum Gene Ther 2002; 13: 803-813.

17 Minotti AM, Barlow SB, Cabral F. Resistance to antimitotic drugs in Chinese hamster ovary cells correlates with changes in the level of polymerized tubulin. $J$ Biol Chem 1991; 266: 3987-3994. 


\section{Supplementary Figure Legends}

Supplementary Figure 1. Mebendazole inhibits expression of c-MYB targets in AML cells. QPCR analysis of selected c-MYB target gene expression in THP1 cells after 6 hours treatment with DMSO or $10 \mu \mathrm{M}$ mebendazole, normalized to DMSO controls. Bars and error bars are means and SD of three independent experiments. ** $P<0.01$; *** $P<0.001$; **** $P<$ 0.0001; n.s. not significant (relative to DMSO controls), one sample $t$ test.

Supplementary Figure 2. Mebendazole inhibits growth and induces apoptosis in AML cells. (a) The chart shows the fold change in viable cell number of AML cell lines treated with DMSO or $10 \mu \mathrm{M}$ mebendazole, over 72 hours. Symbols and error bars are means and SD of three independent experiments, each in triplicate. (b) Examples of Annexin V/PI staining of THP1 cells exposed to DMSO or $10 \mu \mathrm{M}$ mebendazole for 48 hours. (c) Apoptotic analysis of AML cell lines exposed to DMSO or $10 \mu \mathrm{M}$ mebendazole, over 72 hours. Symbols, representing the percentage of Annexin $\mathrm{V}^{-} / \mathrm{PI}^{-}$cells, and error bars are means and SD of three independent experiments.

Supplementary Figure 3. Mebendazole inhibits colony formation by AML cells. Colony formation, normalized to DMSO controls, of AML cell lines in the presence of indicated mebendazole concentrations. Bars and error bars are means and SD of three independent experiments, each in quadruplicate.

Supplementary Figure 4. $c-M Y B$ silencing inhibits colony formation by AML cells. (a) Western blot analysis of c-MYB protein expression in AML cells transduced with control scramble (SCR) shRNA or shRNA targeting c-MYB (MYB). (b) Example of colony formation in methylcellulose cultures of shSCR or shMYB transduced THP1 cells. (c) Colony formation, normalized to DMSO controls, of shSCR or shMYB transduced AML cell lines. Bars and error bars are means and SD of quadruplicate cultures. 
Supplementary Figure 5. Proteasomal inhibition blocks mebendazole induced c-MYB degradation. Quantification of c-MYB protein expression in indicated AML cells lines following 6 hours treatment with DMSO, $10 \mu \mathrm{M}$ MBZ or $10 \mu \mathrm{M}$ MBZ/10 $\mu \mathrm{M}$ MG132. Bars and error bars are means and SD of four (THP1) and three (OCI-AML3, SHI-1) independent experiments. Data are normalized to DMSO controls. $* * * P<0.001$; n.s. not significant (relative to DMSO controls), one sample $t$ test.

Supplementary Figure 6. Mebendazole induces c-MYB degradation at lower concentrations than those required for tubulin depolymerization. (a) Example of western blot analysis of tubulin depolymerization assay. Polymerized tubulin, present in the lysate pellet $(\mathrm{P})$, and soluble tubulin (S) bands are shown for THP1 cells treated for 6 hours with indicated concentrations of mebendazole (top) or colcemid and $5 \mu \mathrm{M}$ paclitaxel (Pax) (bottom). (b) Percent polymerized tubulin in OCI-AML3 cells following 6 hours treatment with indicated concentrations of mebendazole (top left) or colcemid (top right), and western blot analysis of corresponding c-MYB protein expression (bottom). Tubulin stabilization by $5 \mu \mathrm{M}$ paclitaxel (Pax) is also shown. Bars and error bars are means and SD, respectively, of four independent experiments. ${ }^{*} P<0.05 ; * * * P<0.001$, n.s. not significant, unpaired Student's t-test.

Supplementary Figure 7. Mebendazole induced c-MYB loss is not due to cell cycle inhibition. (a) Quantification of c-MYB protein expression in THP1 cells following 4 hours treatment with DMSO or indicated concentrations of mebendazole. Bars and error bars are means and SD of four independent experiments. Data are normalized to DMSO controls. (b) Apoptotic analysis of THP1 cells following 4 hours exposure to DMSO or $10 \mu \mathrm{M}$ mebendazole. Bars, representing the percentage of Annexin $\mathrm{V}^{-} / \mathrm{PI}^{-}$cells, and error bars are means and SD of three independent experiments. (c) Examples of flow cell cycle cytometry plots of THP1 cells treated for 4 hours with DMSO or the indicated concentrations of 
mebendazole. Numbers inside plots are percentages of cells in Go/G1 (bottom left), S (top) and G2/M (bottom right) phases of the cell cycle. (d and e) Bars and error bars are means and SD of percentages of THP1 cells in the Go/G1, S and G2/M phases of the cell cycle following 4 (d) and 24 (e) hours of treatment with DMSO or the indicated concentrations of mebendazole, from four (d) and three (e) independent experiments. ${ }^{*} * * P<0.001$; n.s. not significant, unpaired Student's t-test.

Supplementary Figure 8. Nematic protein organisation technique (NPOT) analysis of mebendazole in AML cell lysates. (a) Pictures of three independent hetero-assemblies (circled in red) induced by mebendazole in primary AML sample AML4298 and THP1 cell lysates. (b) Venn diagrams for the number of proteins identified in AML4298 and THP1 lysates, and in both lysates. (c) DAVID analysis and the annotation sources GOTERM_BP2 (Biological process) were used to identify the functional categories identified in AML4298 lysates. Shown in bold are the proteins comprising the 'protein folding' category also identified in THP1 lysates.

Supplementary Figure 9. The HSP70/HSC70 chaperone complex binds c-MYB and is required for maintenance of c-MYB protein expression. (a) Western blot analysis of mouse IgG and anti-c-MYB immunoprecipitates from THP1 cells, stained with anti-HSP70/HSC70 (top) and anti-c-MYB (bottom). Representative data from one of three independent experiments. (b) Quantification of HSP70 (left) and c-MYB (right) protein expression in THP1 cells 7 days after transduction with control scramble (shSCR) shRNA or two independent shRNA targeting HSPAIA (sh1 and sh2). Bars and error bars are means and SD of three independent experiments. (c) Representative data and quantification of c-MYB protein expression in THP-1 cells after 6 hours treatment with DMSO or the indicated concentrations of the HSP70 inhibitors, KNK437 and VER-155008. Bars and error bars are means and SD of three independent experiments. (d) Representative data and quantification 
of HSP70/HSC70 protein expression in total (total), cytoplasmic (cyto) and nuclear (nuc) extracts from THP-1 cells treated with DMSO or $10 \mu \mathrm{M}$ mebendazole for 6 hours. The extracts were validated using antibodies against $\alpha$ Tubulin (cytoplasmic) and SP1 (nuclear), and nuclear expression of c-MYB is also shown. Bars and error bars represent relative HSP70/HSC70 expression in total (using $\alpha$ Tubulin for loading), cytoplasmic (using $\alpha$ Tubulin for loading) and nuclear extracts (using SP1 for loading), and are means and SD of three independent experiments. ${ }^{*} P<0.05$; $* * P<0.01$; $* * * P<0.001$; n.s. not significant (relative to DMSO controls), one sample $t$ test.

Supplementary Figure 10. Mebendazole pre-treatment inhibits colony formation by primary AML cells but not $\mathrm{CD} 34^{+} \mathrm{CB}$ cells. (a) Example of colony formation by a primary AML patient sample (AML1547) and a normal $\mathrm{CD}^{+} 4^{+}$cord blood sample (CB1), after pretreatment with DMSO or $10 \mu \mathrm{M}$ mebendazole. Cells were treated with vehicle or drug for 20 hours, washed and placed into methylcellulose culture. Colonies were grown for 14 days and visualized by staining with $1 \mathrm{mg} / \mathrm{ml}$ p-iodonitrotetrazolium. (b) CFU-G, CFU-GM, BFU-E, CFU-M, CFU-GEMM and total colony numbers of two independent normal CD34 ${ }^{+}$cord blood samples (CB1, CB2) after pre-treatment with DMSO or $10 \mu \mathrm{M}$ mebendazole. Cells were treated with vehicle or drug for 20 hours, washed and placed into methylcellulose culture, and colony formation scored 14 days later.

Supplementary Figure 11. Mebendazole induced c-MYB loss in CB cells is less acute than in AML cells. (a) Representative data and (b) quantification of c-MYB protein expression in CB cells following treatment with DMSO or $10 \mu \mathrm{M}$ mebendazole for 6 hours. Prior to drug treatment, $\mathrm{CD} 34^{+} \mathrm{CB}$ cells were expanded for 7 days. Bars and error bars are means and SD of data from three independent $\mathrm{CB}$ samples. ${ }^{*} P<0.05$ (relative to DMSO controls), one sample $t$ test. 
Supplementary Figure 12. In vivo drug treatment selects for increased c-MYB expression and reduced sensitivity to mebendazole. (a) Quantification of c-MYB protein expression in THP1 cells ex vivo (T-RES1), isolated from NSG mice following treatment with mebendazole in vivo, compared to control THP1 cells. (b) Increased c-MYB expression is still exhibited after two weeks in vitro culture in the absence of mebendazole. c-MYB protein expression in THP1 cells isolated from mebendazole-treated NSG mice (T-RES1 and TRES2) following 2 weeks in vitro culture (in vitro). (c) c-MYB protein expression in T-RES1 cells, after 6 hours ex vivo exposure to the indicated concentrations of mebendazole, compared to control THP1 cells. (d) Viability, normalized to DMSO controls, of control THP1 and T-RES1 cells treated for 72 hours with indicated mebendazole concentrations. Bars and error bars are means and SD of triplicate cultures. 
Supplementary Table 1. Patient characteristics.

\begin{tabular}{l|c|c|c|l} 
Patient id & Sex & Age $($ yrs $)$ & FAB & Karyotype \\
\hline 1497 & M & 1.6 & 4 & 46, XY, t $(9 ; 11 ; 9)(\mathrm{p} 22 ; \mathrm{p} 23 ; \mathrm{q} 34)$ \\
1547 & F & 8.8 & 5 & $46, \mathrm{XX}, \mathrm{t}(9 ; 11)(\mathrm{p} 22 ; \mathrm{q} 23)($ low\% 47, idem, +8) \\
4298 & M & 11.2 & 5 & $46, \mathrm{XY}, \mathrm{t}(9 ; 11)$
\end{tabular}


Supplementary Table 2. Gene expression data for SPIEDw analysis.

\begin{tabular}{|c|c|}
\hline Gene & Fold change upon loss of MLL-ENL/MLL-AF9 \\
\hline ANTXR1 & -14.040 \\
\hline SIX4 & -9.696 \\
\hline P2RY2 & -7.474 \\
\hline FRAT2 & -6.627 \\
\hline IRAK1BP1 & -5.853 \\
\hline IPO11 & -5.278 \\
\hline LRIG1 & -4.860 \\
\hline SIX1 & -3.968 \\
\hline TASP1 & -3.809 \\
\hline CABLES1 & -3.734 \\
\hline MYC & -3.724 \\
\hline MMACHC & -3.586 \\
\hline PDCD4 & -3.571 \\
\hline NT5DC2 & -3.562 \\
\hline PDXK & -3.490 \\
\hline ST7 & -3.435 \\
\hline MID1 & -3.373 \\
\hline SPRED1 & -3.043 \\
\hline PFKL & -3.026 \\
\hline HSPA2 & -2.994 \\
\hline MRPS27 & -2.957 \\
\hline PRMT6 & -2.933 \\
\hline SLC39A8 & -2.867 \\
\hline MRPS6 & -2.862 \\
\hline MSI2 & -2.786 \\
\hline GATA2 & -2.744 \\
\hline UCK2 & -2.714 \\
\hline STEAP3 & -2.714 \\
\hline PRPF19 & -2.664 \\
\hline CRTAP & -2.642 \\
\hline EXOSC6 & -2.631 \\
\hline GPR180 & -2.629 \\
\hline LIPT1 & -2.617 \\
\hline PAPSS2 & -2.613 \\
\hline AHCY & -2.607 \\
\hline EBNA1BP2 & -2.563 \\
\hline TMEM97 & -2.558 \\
\hline $\mathrm{ABI} 2$ & -2.554 \\
\hline BAMBI & -2.548 \\
\hline PCDH7 & -2.547 \\
\hline TRAP1 & -2.518 \\
\hline MINPP1 & -2.490 \\
\hline PRPS1 & -2.452 \\
\hline
\end{tabular}




\begin{tabular}{|c|c|}
\hline SPRED2 & -2.409 \\
\hline POLR1E & -2.275 \\
\hline SPRY2 & -2.226 \\
\hline OLA1 & -2.198 \\
\hline LIMK1 & -2.182 \\
\hline COMMD9 & -2.172 \\
\hline NUP35 & -2.151 \\
\hline ACSL3 & -2.149 \\
\hline KLHL5 & -2.147 \\
\hline LPAR1 & -2.132 \\
\hline DTYMK & -2.103 \\
\hline EPRS & -2.099 \\
\hline IDH2 & -2.095 \\
\hline TMEM107 & -2.080 \\
\hline TRIM45 & -2.057 \\
\hline SASH1 & -2.045 \\
\hline CXorf21 & -2.029 \\
\hline BCLAF1 & -2.005 \\
\hline NIT2 & -1.992 \\
\hline SNRPF & -1.988 \\
\hline IL13RA1 & 1.992 \\
\hline ECM1 & 2.004 \\
\hline AGTRAP & 2.004 \\
\hline RUNX1 & 2.020 \\
\hline CENPJ & 2.024 \\
\hline PSAP & 2.037 \\
\hline PTPRC & 2.041 \\
\hline DACH1 & 2.053 \\
\hline FMNL1 & 2.053 \\
\hline SULF2 & 2.058 \\
\hline SLA & 2.070 \\
\hline SSH1 & 2.070 \\
\hline PTK2B & 2.070 \\
\hline ABCG1 & 2.088 \\
\hline PLEK & 2.092 \\
\hline INTS12 & 2.096 \\
\hline TDRD7 & 2.119 \\
\hline PLEKHO2 & 2.123 \\
\hline CDC42EP3 & 2.132 \\
\hline RBMS1 & 2.132 \\
\hline IQSEC1 & 2.132 \\
\hline FHOD1 & 2.141 \\
\hline LST1 & 2.146 \\
\hline H2AFX & 2.151 \\
\hline NUMB & 2.160 \\
\hline ACVR1B & 2.165 \\
\hline ABCA13 & 2.165 \\
\hline IQGAP1 & 2.174 \\
\hline
\end{tabular}




\begin{tabular}{|c|c|}
\hline TOB 1 & 2.174 \\
\hline WDR26 & 2.174 \\
\hline PLEKHA2 & 2.179 \\
\hline DMXL2 & 2.217 \\
\hline AKAP13 & 2.222 \\
\hline MAPK3 & 2.227 \\
\hline PRKCD & 2.252 \\
\hline IFT122 & 2.257 \\
\hline PIK3CB & 2.262 \\
\hline HBP1 & 2.304 \\
\hline $\mathrm{SSH} 2$ & 2.309 \\
\hline PTPRE & 2.326 \\
\hline LPP & 2.342 \\
\hline SH3KBP1 & 2.347 \\
\hline PYGL & 2.347 \\
\hline MBP & 2.381 \\
\hline WIPI1 & 2.381 \\
\hline HEXB & 2.410 \\
\hline RTKN2 & 2.427 \\
\hline TNFAIP3 & 2.451 \\
\hline PHF21A & 2.457 \\
\hline KLF13 & 2.457 \\
\hline GLRX & 2.481 \\
\hline FLNA & 2.488 \\
\hline NCF4 & 2.494 \\
\hline PSTPIP2 & 2.513 \\
\hline FLOT1 & 2.525 \\
\hline SMARCA2 & 2.538 \\
\hline NEU1 & 2.558 \\
\hline SNX10 & 2.558 \\
\hline RAC2 & 2.591 \\
\hline SIRPA & 2.660 \\
\hline VCAN & 2.667 \\
\hline SEMA4D & 2.695 \\
\hline ITGAL & 2.710 \\
\hline JAZF1 & 2.747 \\
\hline KLF6 & 2.762 \\
\hline IQGAP2 & 2.778 \\
\hline $\mathrm{BMX}$ & 2.786 \\
\hline MYO1F & 2.874 \\
\hline SORL1 & 2.882 \\
\hline LTA4H & 2.890 \\
\hline PELI2 & 2.907 \\
\hline ACSL1 & 2.933 \\
\hline MYH9 & 2.933 \\
\hline SPSB1 & 2.976 \\
\hline SNAI3 & 3.012 \\
\hline CD9 & 3.012 \\
\hline
\end{tabular}




\begin{tabular}{|c|c|}
\hline RHBDF2 & 3.030 \\
\hline CCND3 & 3.040 \\
\hline THBS1 & 3.077 \\
\hline DOCK5 & 3.125 \\
\hline LGALS3 & 3.226 \\
\hline PLAUR & 3.268 \\
\hline ZFP36 & 3.390 \\
\hline ZYX & 3.390 \\
\hline ZFP36L1 & 3.509 \\
\hline GLIPR2 & 3.636 \\
\hline DHRS3 & 3.650 \\
\hline NOTCH1 & 3.676 \\
\hline ST3GAL2 & 3.690 \\
\hline NFKBIZ & 3.831 \\
\hline PLAU & 3.906 \\
\hline LTB4R & 3.922 \\
\hline NCF1 & 4.000 \\
\hline FGR & 4.219 \\
\hline LYST & 4.237 \\
\hline DAPK2 & 4.274 \\
\hline PHLDA1 & 4.367 \\
\hline BCL6 & 4.425 \\
\hline SQRDL & 4.785 \\
\hline GPAT3 & 5.181 \\
\hline GCNT2 & 5.435 \\
\hline HLX & 6.024 \\
\hline SERPINB2 & 6.452 \\
\hline S100A4 & 8.130 \\
\hline EGR2 & 9.259 \\
\hline CAMP & 9.434 \\
\hline PLP2 & 9.615 \\
\hline $\mathrm{HCK}$ & 9.709 \\
\hline PRAM1 & 12.422 \\
\hline C5AR1 & 13.889 \\
\hline
\end{tabular}




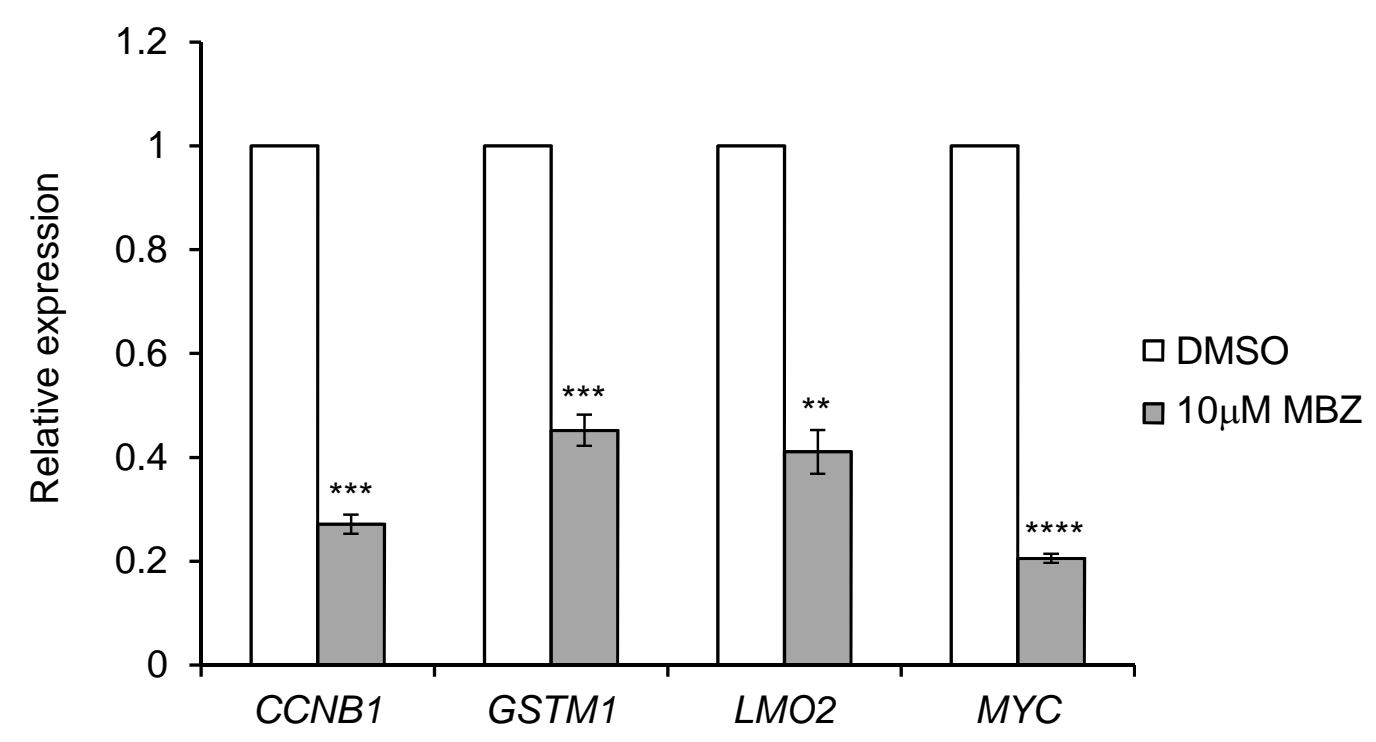

SUPPLEMENTARY FIGURE 1 


\section{a}
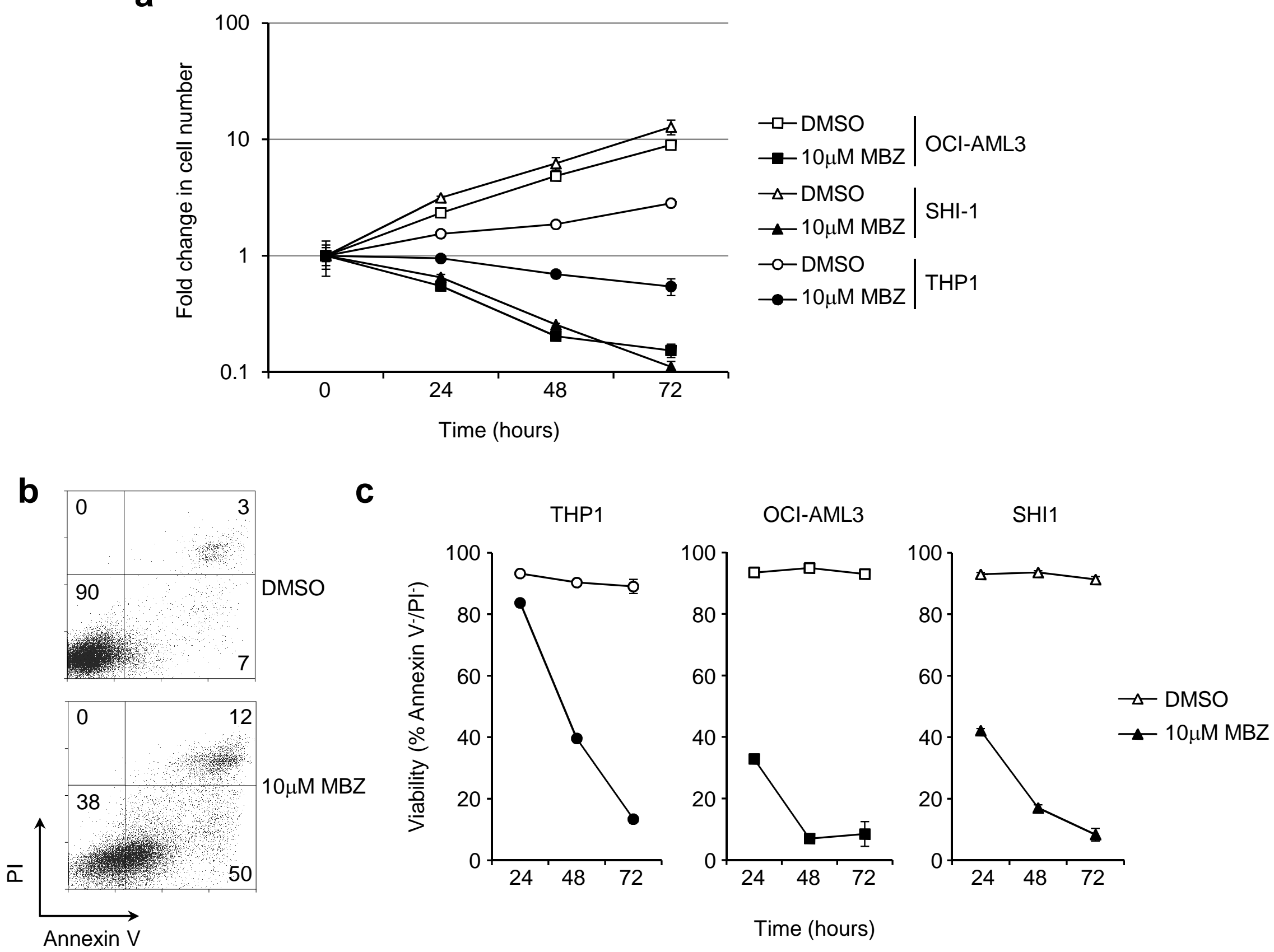

\section{SUPPLEMENTARY FIGURE 2}



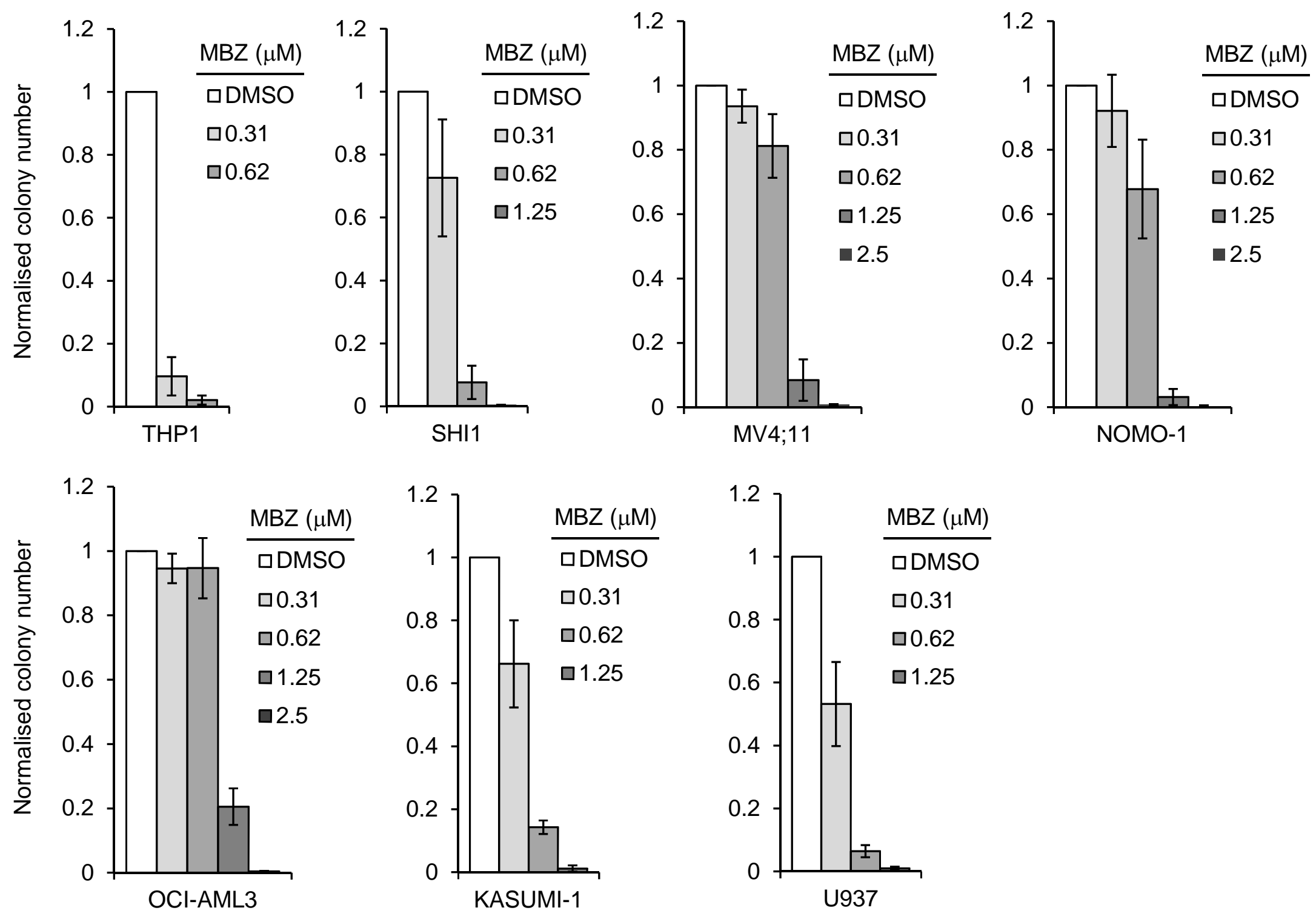

\section{SUPPLEMENTARY FIGURE 3}


a

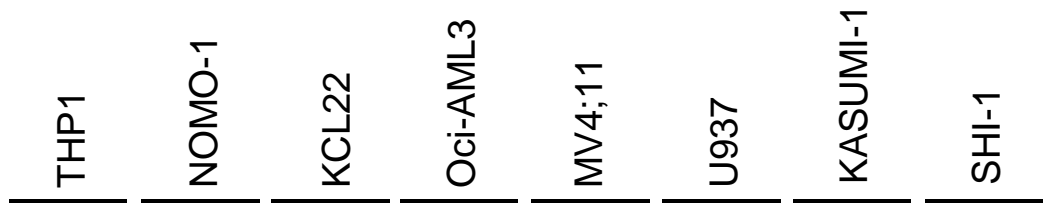

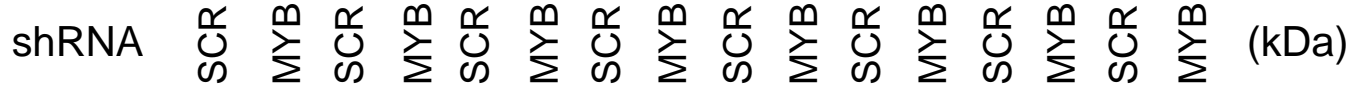

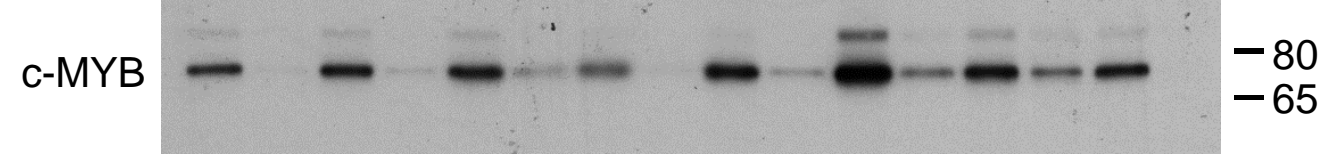

ACTIN

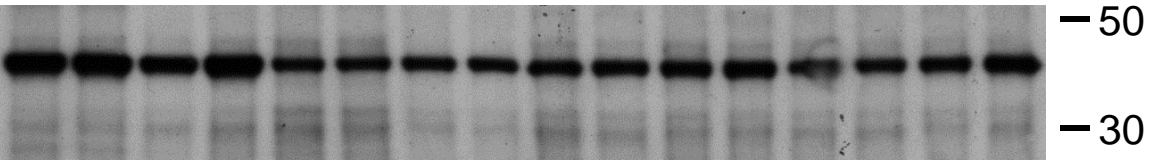

b

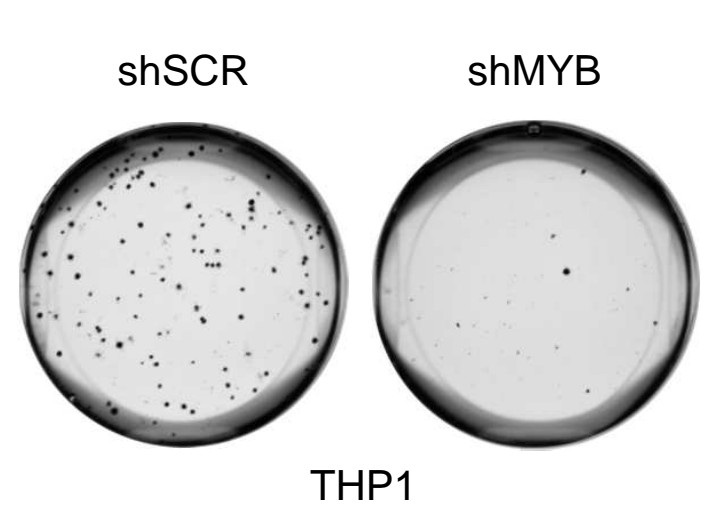

C

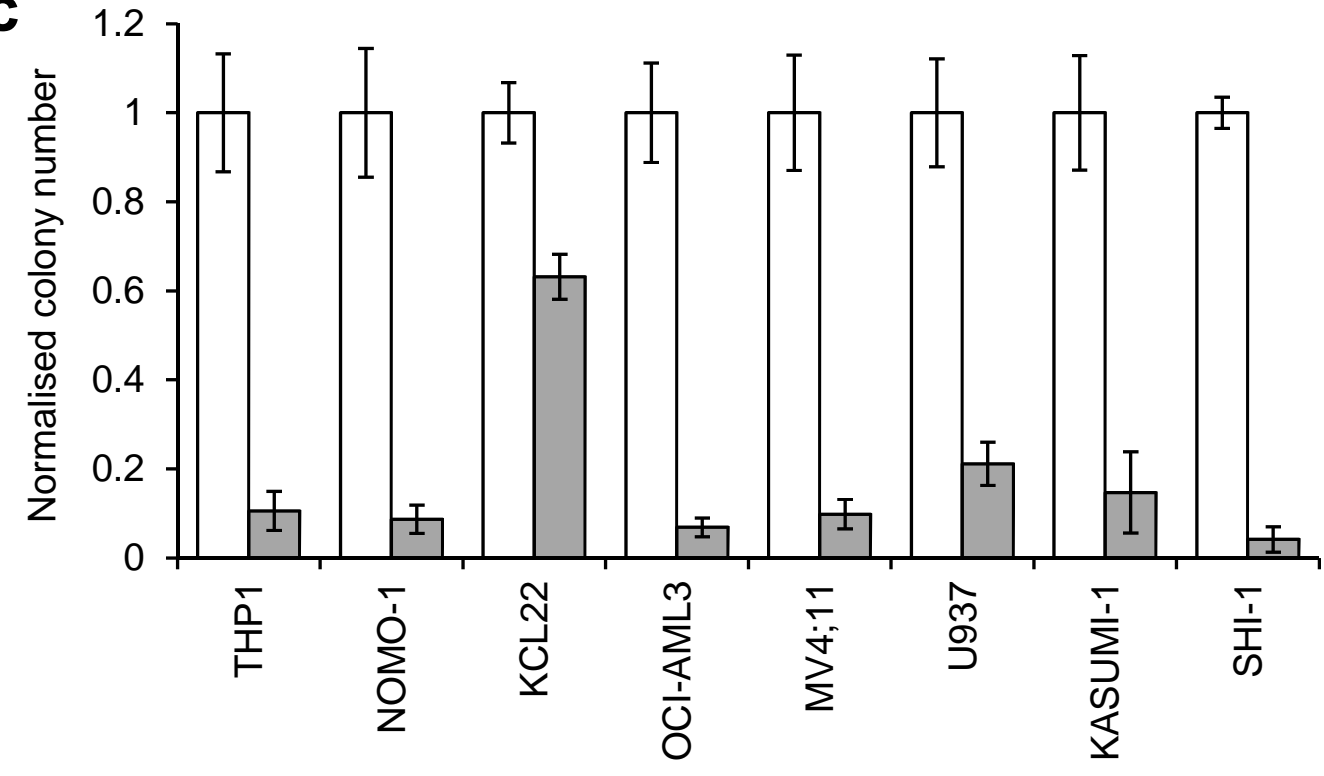

口shSCR

口ShMYB 


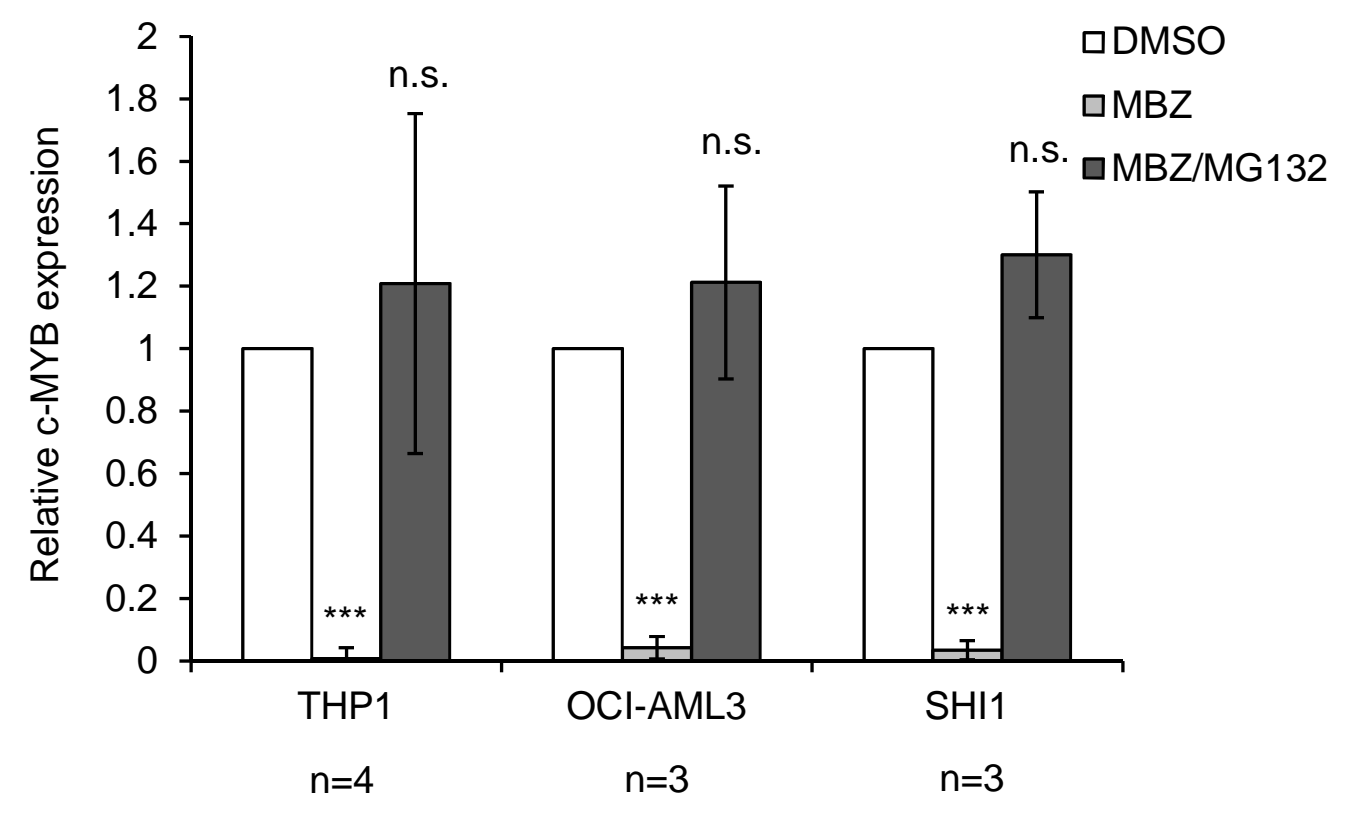

SUPPLEMENTARY FIGURE 5 
a THP1

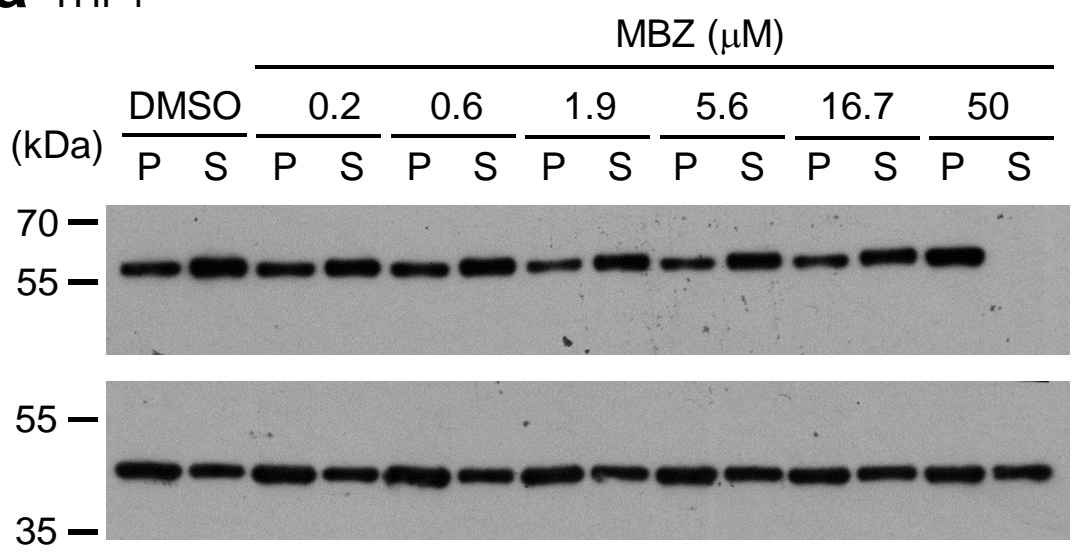

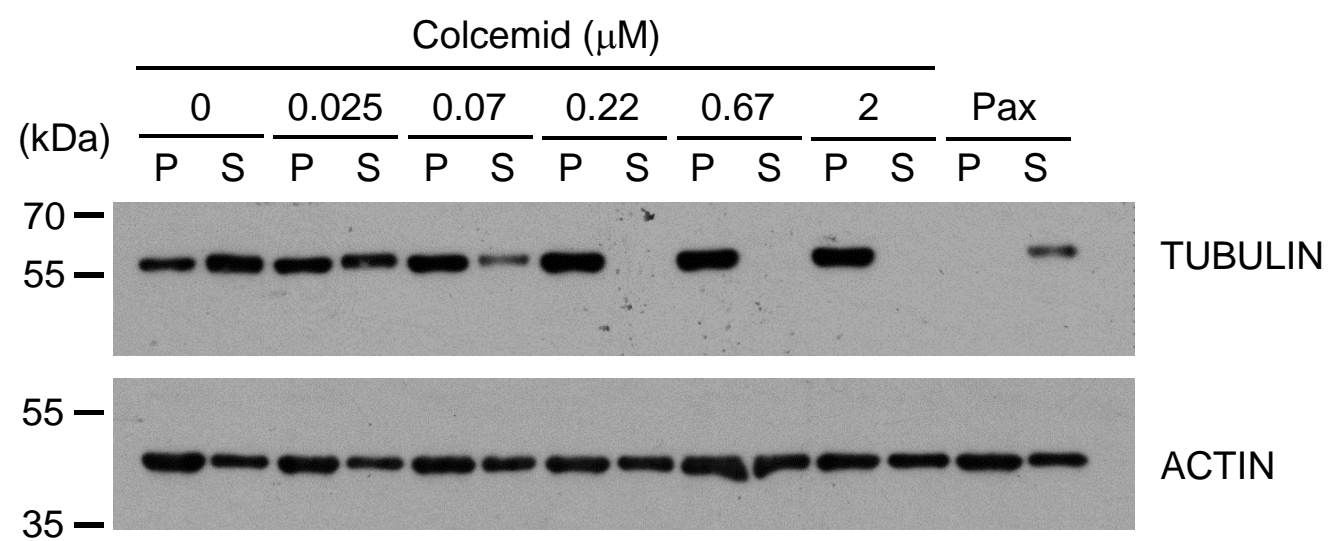

b OCI-AML3
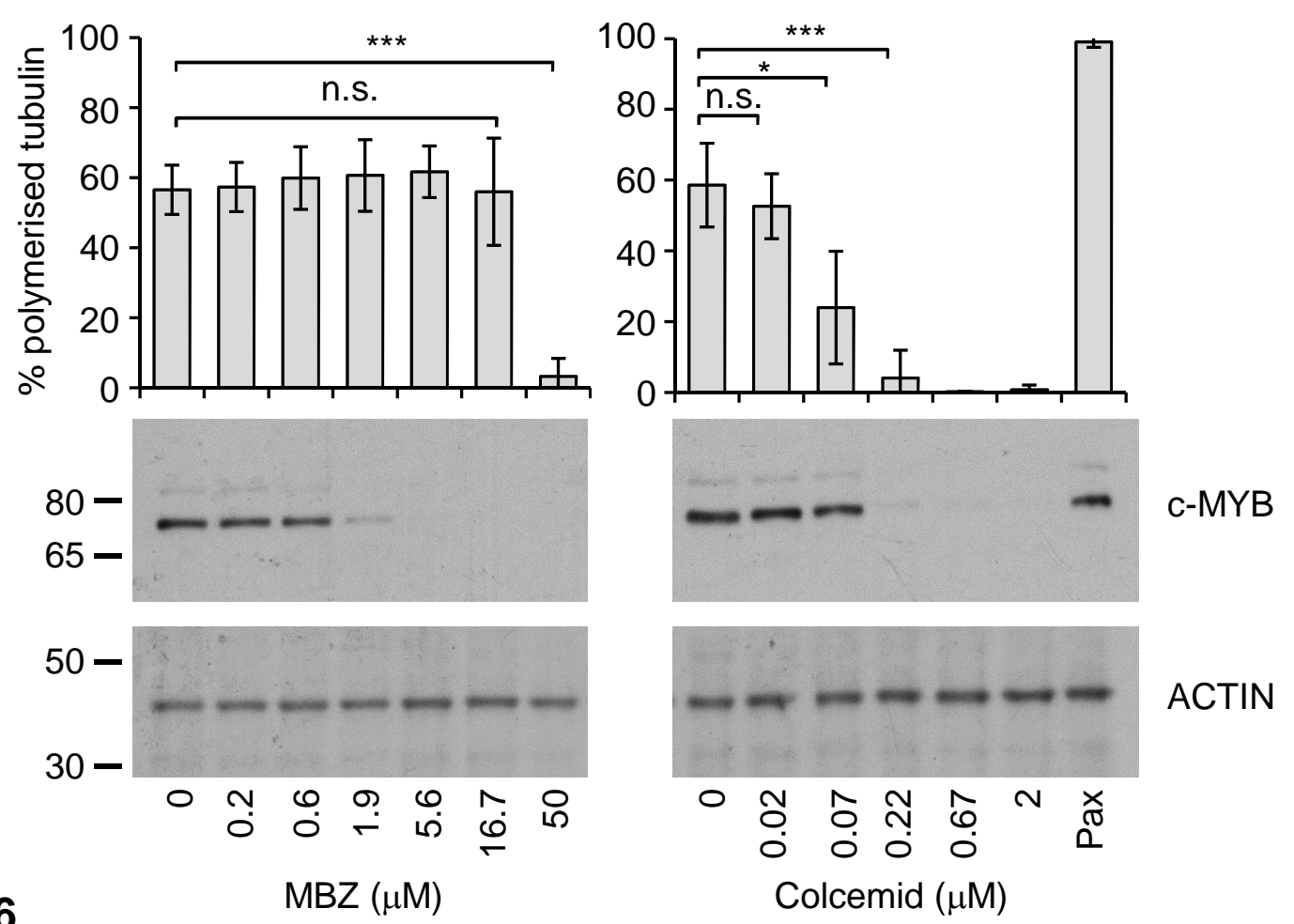

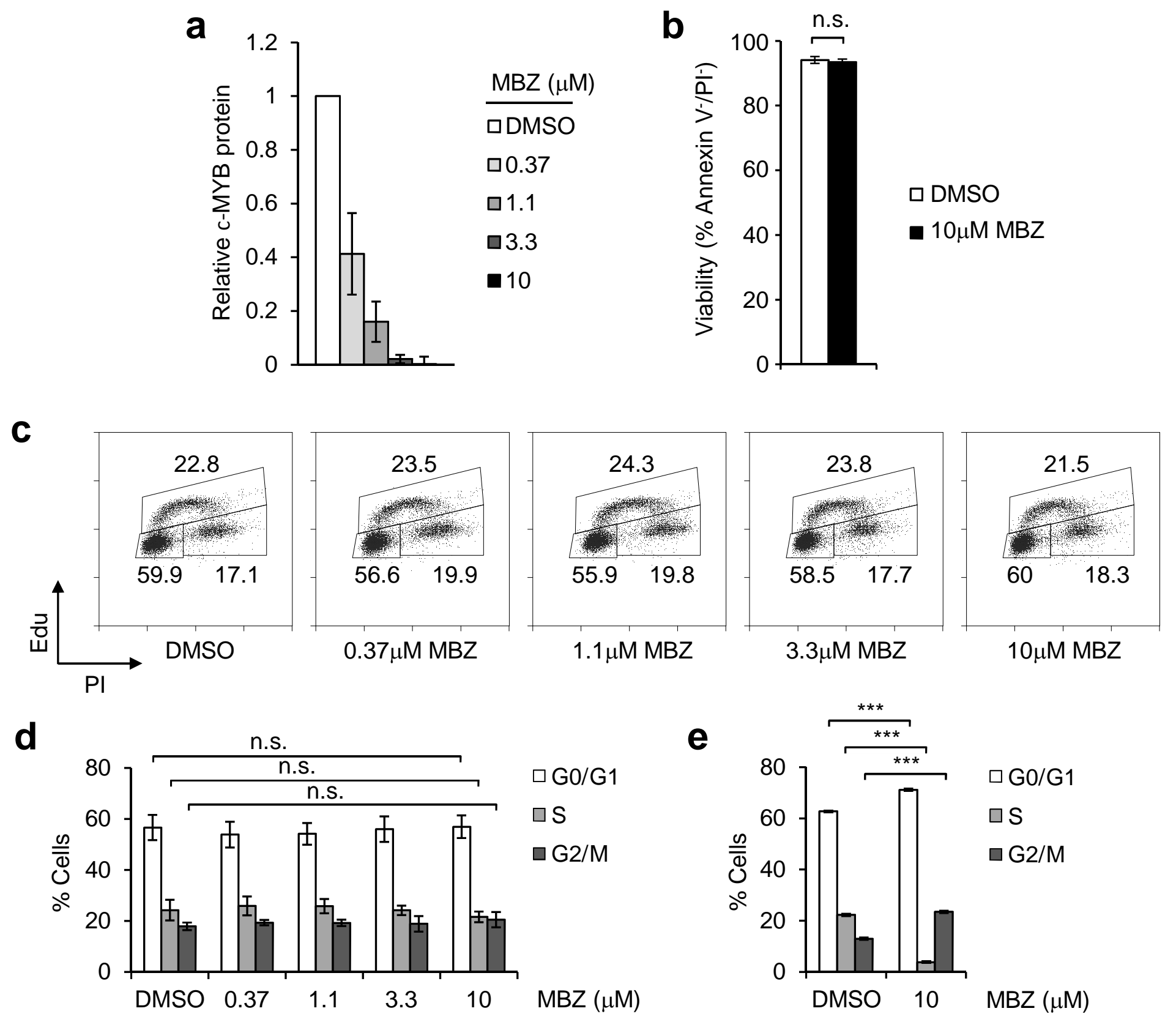

\section{SUPPLEMENTARY FIGURE 7}


b
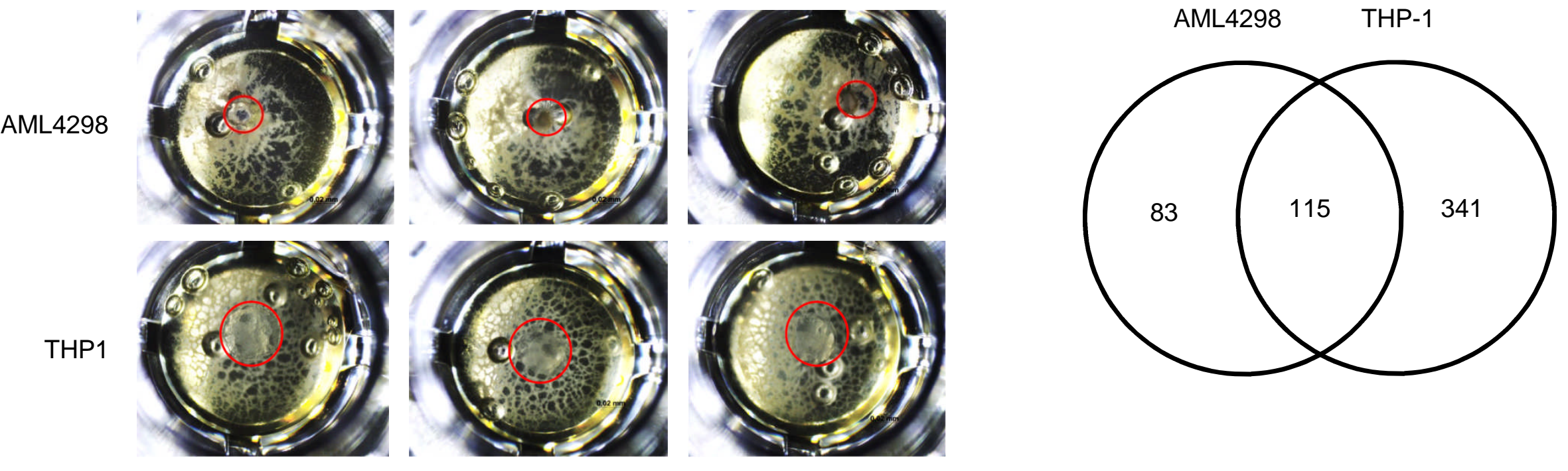

C

David analysis patient sample AML4298 with MBZ

\begin{tabular}{|l|c|l|}
\hline Category & No of Proteins & P value \\
\hline single-organism metabolic process & 86 & $8.00 \mathrm{E}-10$ \\
protein folding & 16 & $6.20 \mathrm{E}-08$ \\
cell adhesion & 44 & $4.40 \mathrm{E}-07$ \\
catabolic process & 48 & $1.10 \mathrm{E}-06$ \\
cellular component biogenesis & 59 & $8.10 \mathrm{E}-06$ \\
\hline
\end{tabular}

\section{SUPPLEMENTARY FIGURE 8}

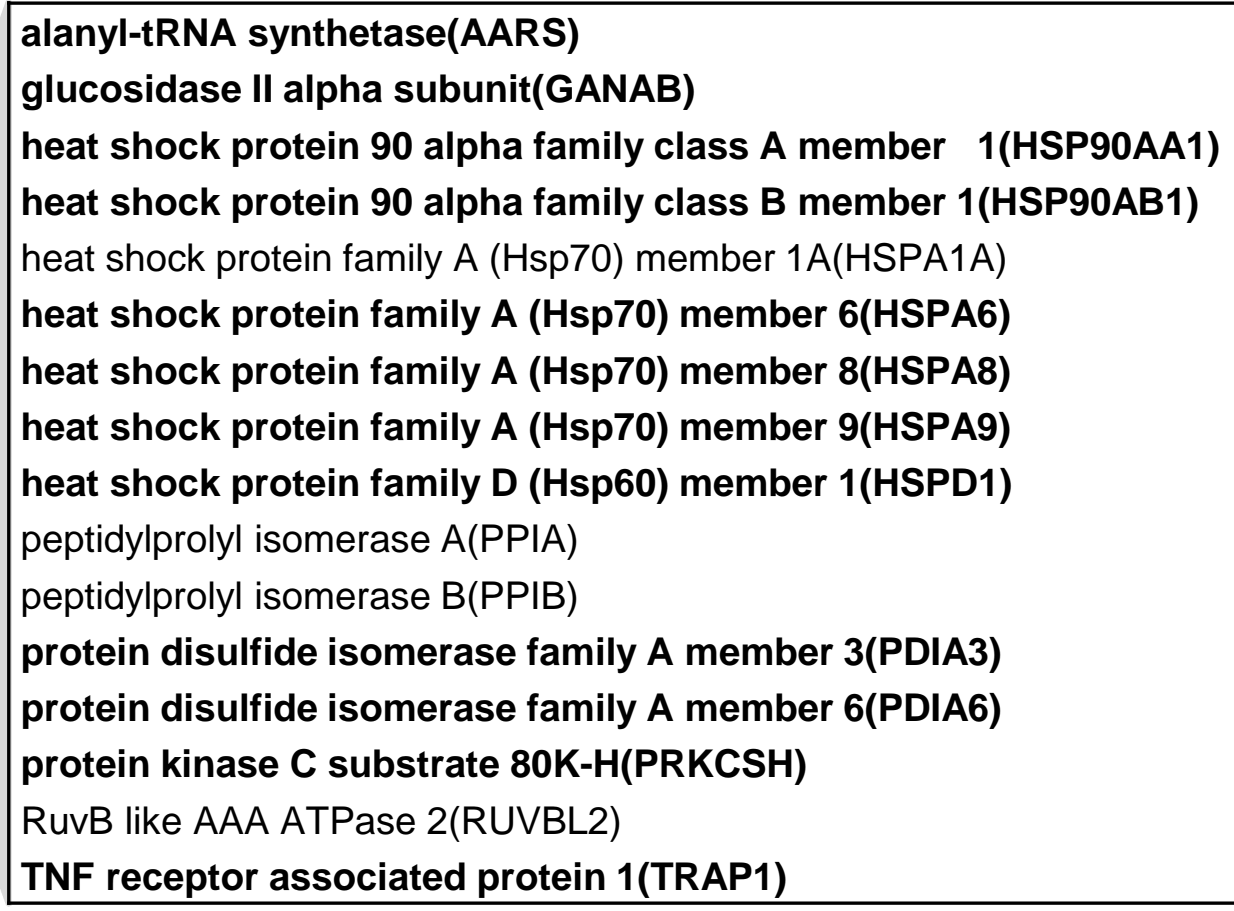

*In bold confirmed in THP-1 cells. 
a

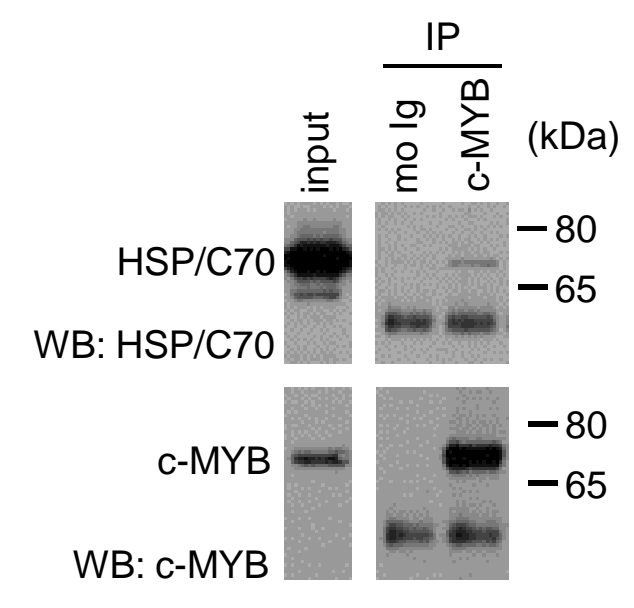

b

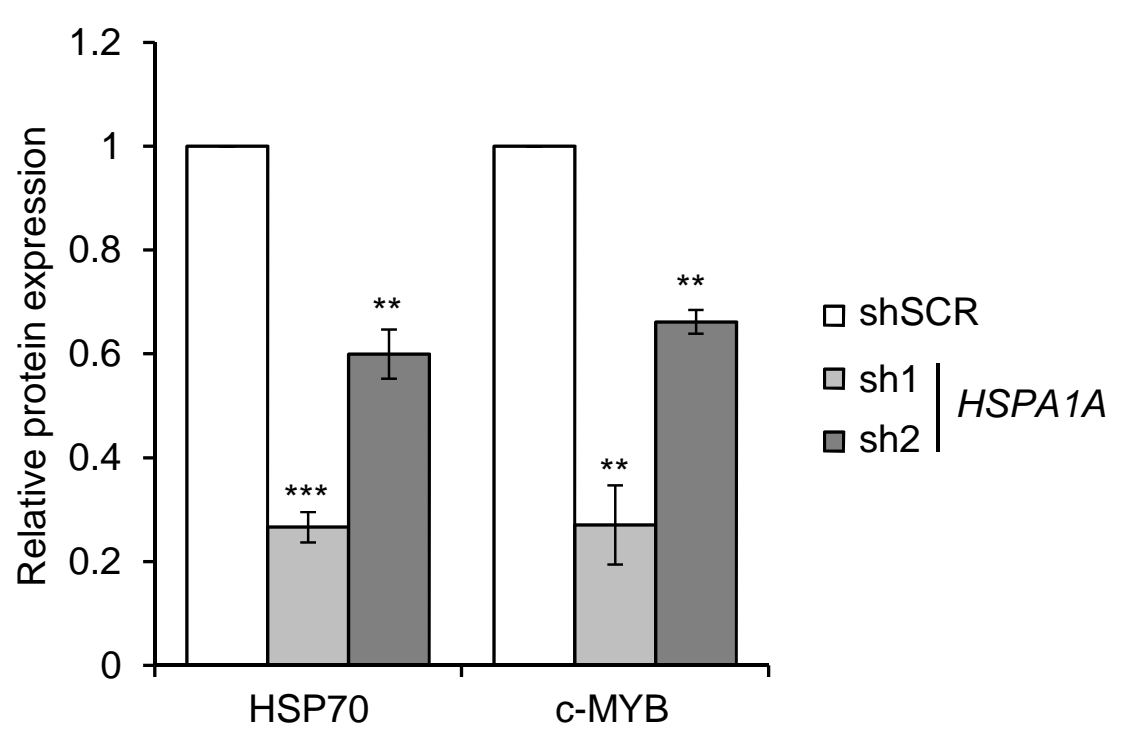

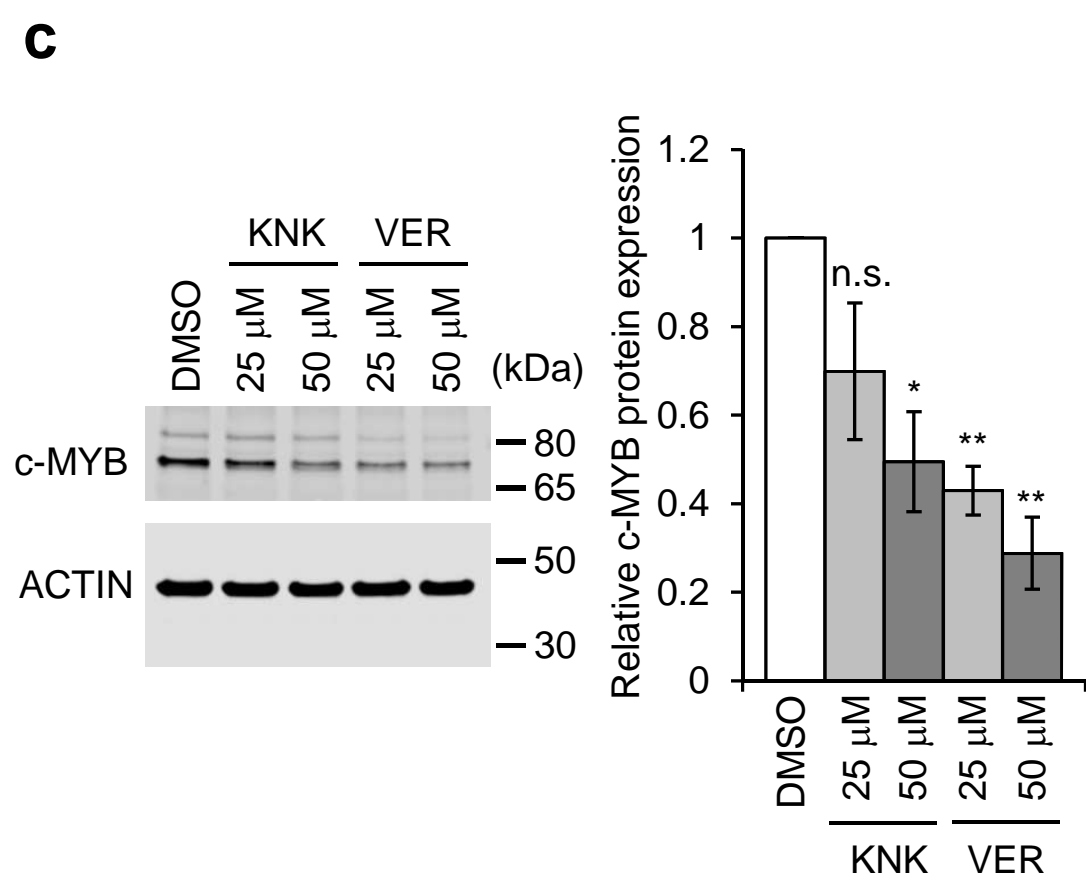

d

d total $\frac{\text { cyto }}{\mathrm{O} \text { nuc }}$

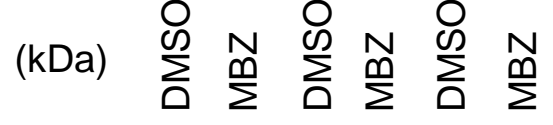

80- $65---ー-ー H S P / C 70$

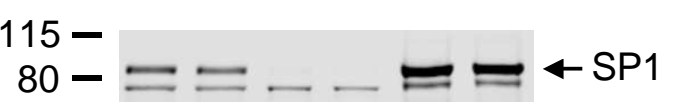

$65-$

$50--ー-\cdots \quad \alpha$ TUBULIN
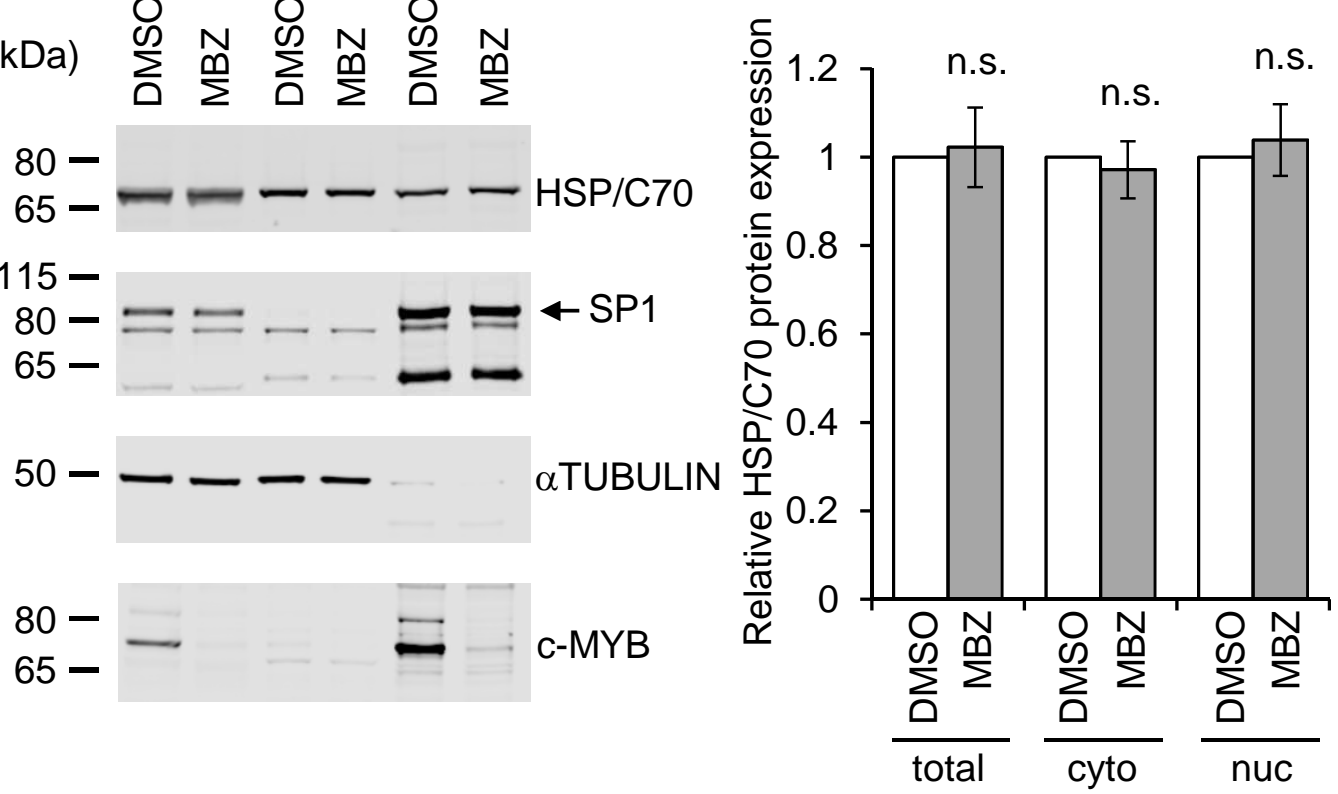

\section{SUPPLEMENTARY FIGURE 9}


a

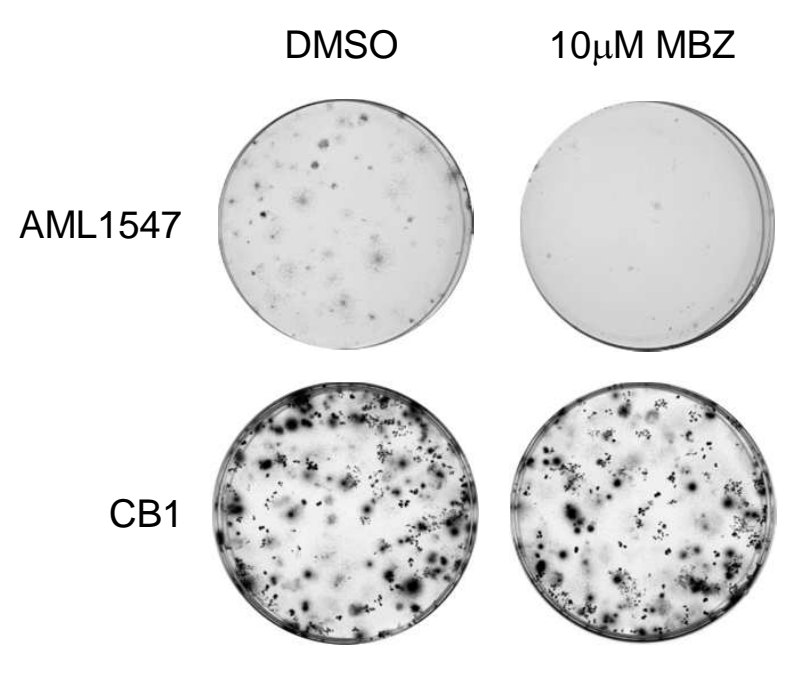

b
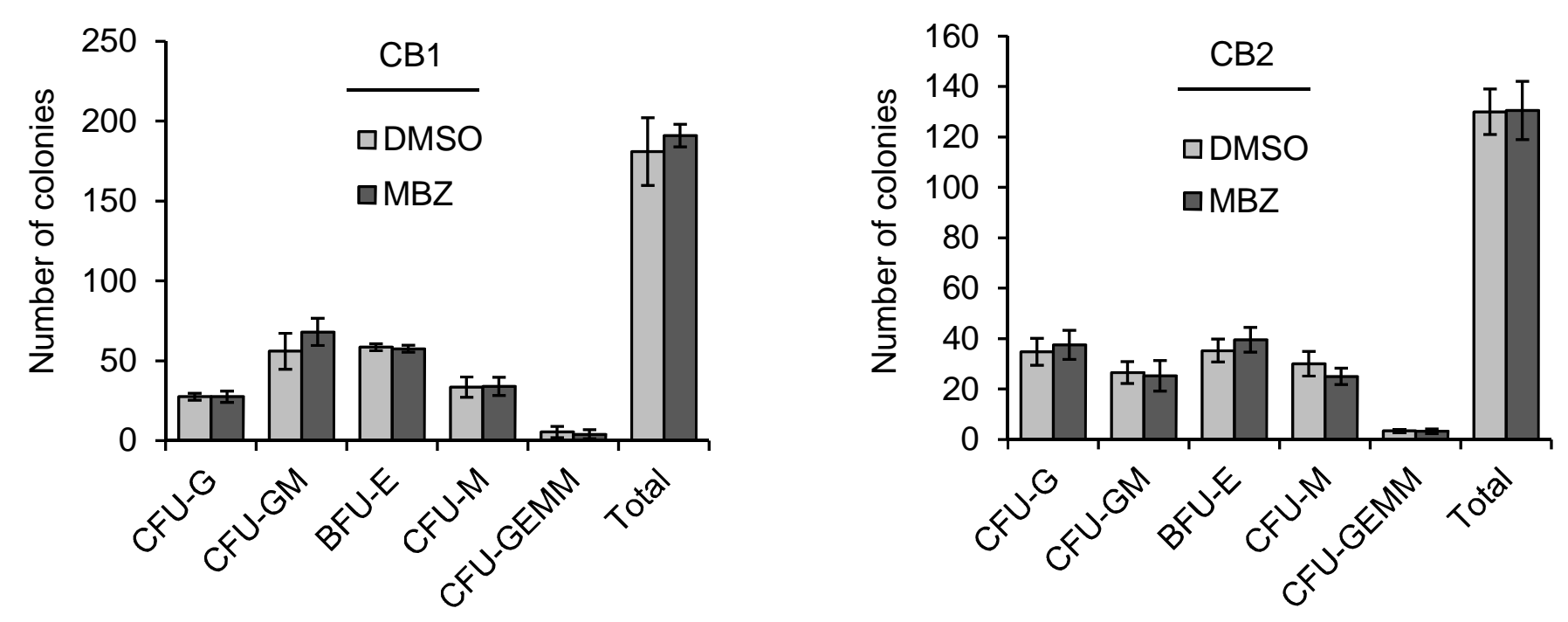
a

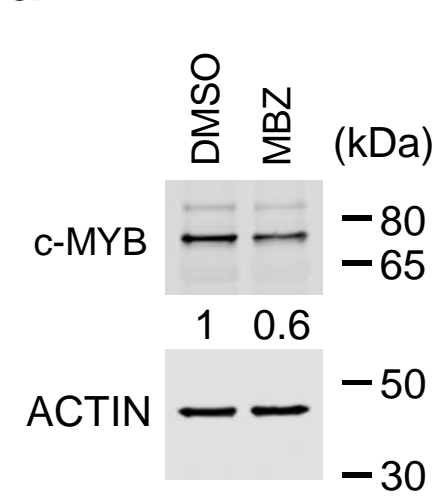

b

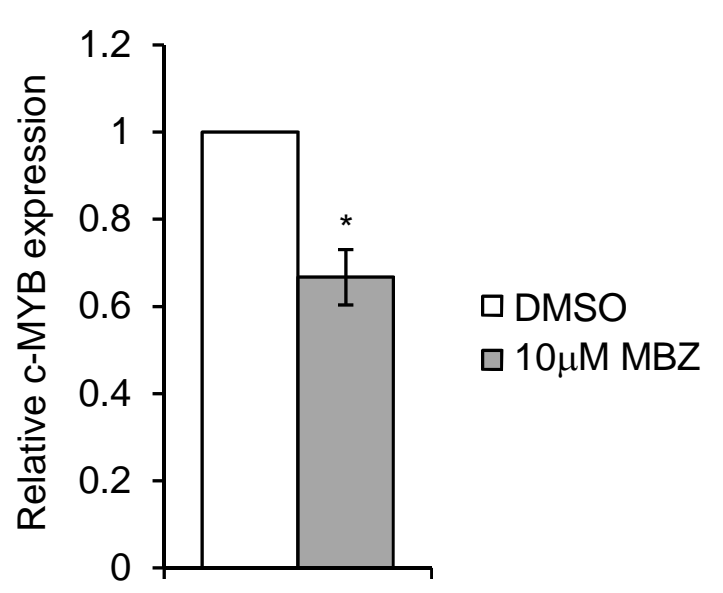


a

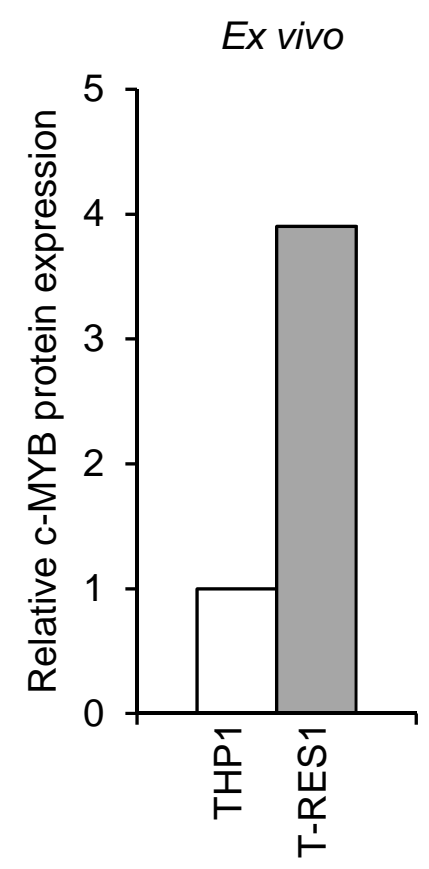

b

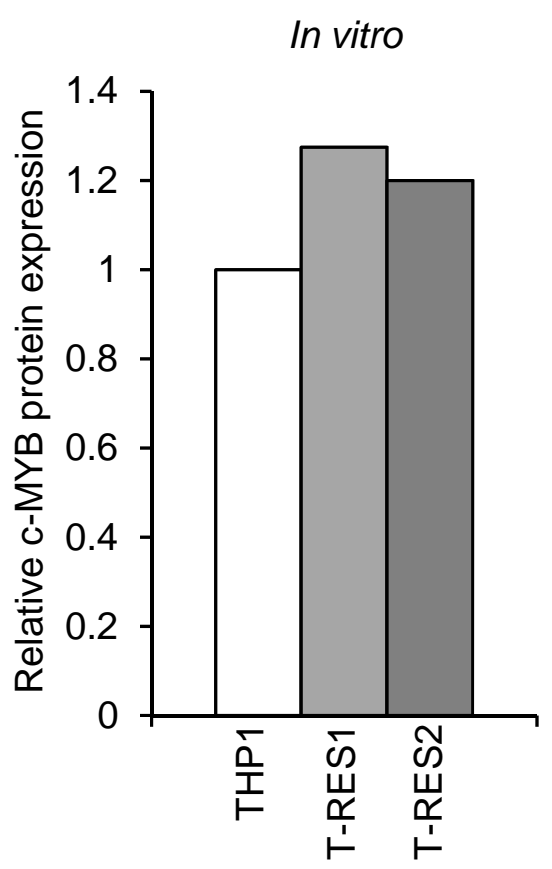

C

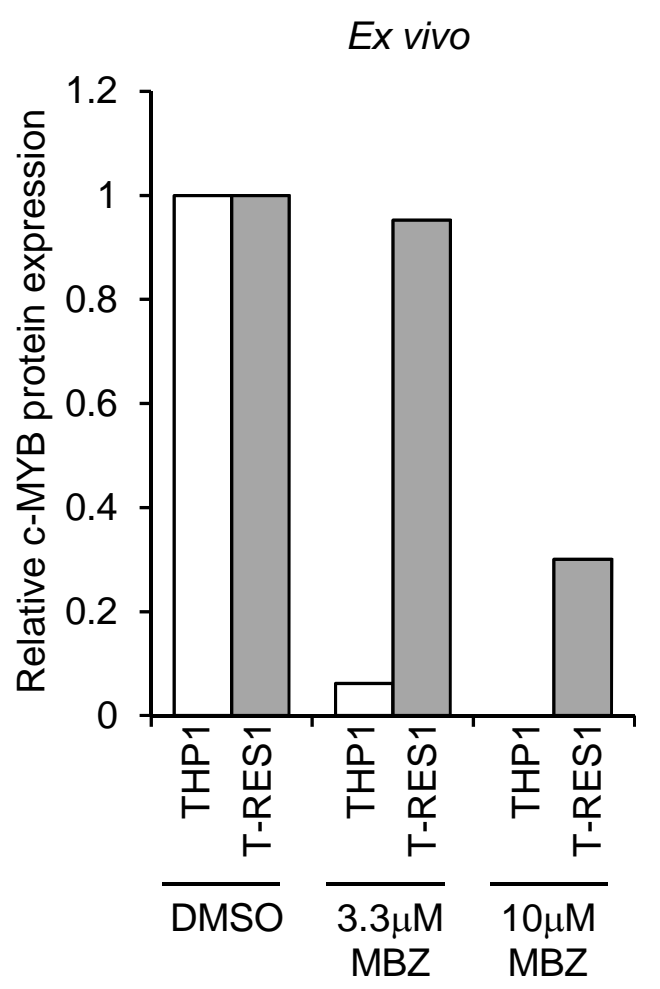

d

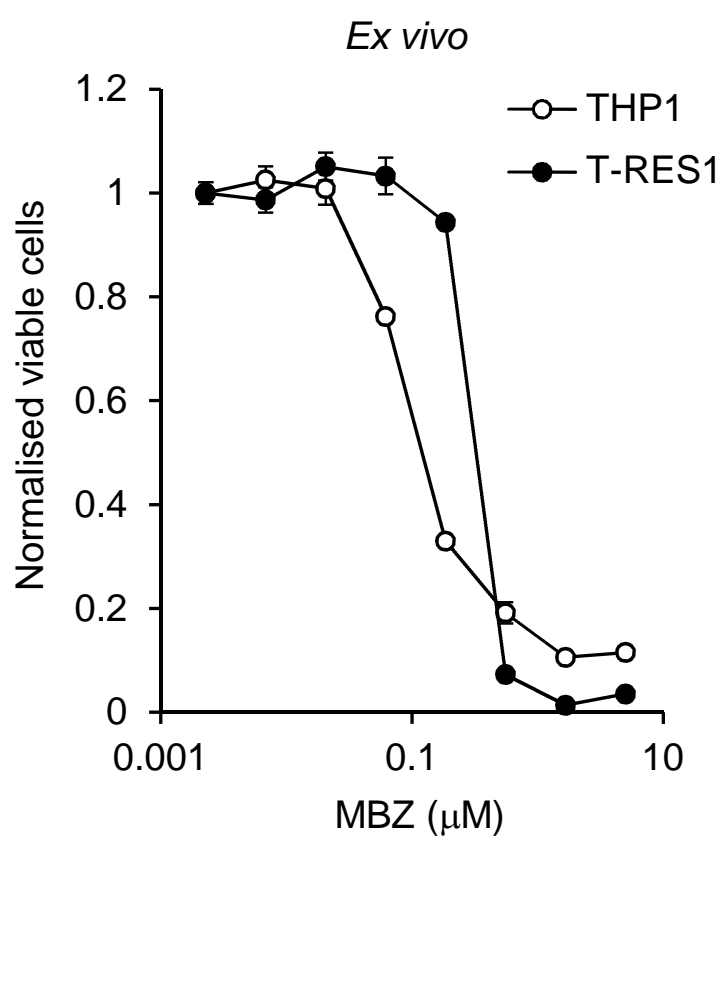

